\title{
Mixed Layer Depth and Sea Surface Warming under Diurnally Cycling Surface Heat Flux in the Heating Season
}

\author{
YUSUKE USHIJIMA AND YUTAKA YOSHIKAWA \\ Graduate School of Science, Kyoto University, Kyoto, Japan
}

(Manuscript received 2 November 2018, in final form 17 April 2019)

\begin{abstract}
In the present study, large-eddy simulations (LESs) were performed to investigate mixed layer depth (MLD) and sea surface warming (SSW) under diurnally cycling surface heat flux in the heating season, in which a mixed layer (ML) is shoaling on intraseasonal time scales. The LES results showed that the diurnal cycle makes the MLD greater (smaller) at lower (higher) latitudes than the MLD without the cycle. Time scales of the wind-induced shear and the surface heat are a key to understand this latitudinal dependence of the diurnal cycle effects. The wind-induced shear-driven turbulence developed from early morning and became strongest at half the inertial period $\left(T_{i} / 2\right)$, while nighttime cooling weakened the ML stratification until the end of the nighttime $\left(T_{24}=24 \mathrm{~h}\right)$. At lower latitudes where $T_{i} / 2>T_{24}\left(\right.$ lower than $\left.15^{\circ}\right)$, the shear-driven turbulence continued to grow after $T_{24}$ and determined the time of the greatest MLD. Thus, the shear-driven turbulence shaped the latitudinal dependence of the MLD, though convective turbulence helped further deepening of the ML. At higher latitudes $\left(T_{i} / 2<T_{24}\right)$, on the other hand, the shear-driven turbulence ceased growing before the nighttime cooling ended. However, reduced stratification due to the nighttime cooling supported the shear-driven turbulence to continue deepening the ML. Thus, the nighttime cooling shaped the latitudinal dependence of the MLD at higher latitudes. The MLD change induced by the diurnal cycle altered the SSW rate. At higher latitudes, the diurnal cycle is expected to reduce the MLD and increase the SSW by $10 \%$ in the heating season.
\end{abstract}

\section{Introduction}

The intense turbulent vertical mixing induced by winds, waves, and convection forms an almost vertically uniform mixed layer (ML) in the surface ocean. The ML depth (MLD) determines the heat capacity of the surface ocean and hence the sea surface temperature (SST) response to given surface heat flux. Since the SST controls the heat exchange between the ocean and atmosphere, the MLD affects air-sea interaction. The MLD is also a key quantity for subduction from the surface layer to greater depths (e.g., Marshall et al. 1993), spring blooming of phytoplankton (e.g., Sverdrup 1953; Obata et al. 1996), and other oceanic processes as well as the air-sea interaction. Therefore, a precise understanding of the MLD dependencies on external forcings is crucially important.

The present study focused on the MLD in the heating season when the MLD is generally smaller. In this

\footnotetext{
Corresponding author: Yusuke Ushijima, usijimay@kugi.kyotou.ac.jp
}

season, the SST response to given surface heat flux is larger due to the smaller heat capacity of the surface ocean. Hence, MLD changes have a larger impact on the atmosphere and the Earth climate system. For example, recent studies using coupled general circulation models (CGCMs) showed that the strength and pattern of the summer monsoons are influenced by the summer MLD (Roxy et al. 2013; Li et al. 2016). Nevertheless, ocean general circulation models (OGCMs) and CGCMs often fail to reproduce quantitatively the summer MLD (Ezer 2000; Huang et al. 2014). This indicates that the processes controlling the MLD in the heating season are not well represented in those models, and these processes need to be investigated and quantified in more detail.

From spring to summer, the ML generally becomes shallower because of the net stabilizing surface heat flux. In the heating season, the heat concentrated in the surface layer inhibits wind-induced turbulence. Thus, the MLD is controlled by the wind stress $\left(\tau=\rho u_{*}^{2}\right.$, where $\rho$ is the water density and $u_{*}$ is the water-side friction velocity) and the stabilizing 
heat flux (or buoyancy flux $B_{f}$ when freshwater flux significantly changes the surface water density). Goh and Noh (2013) performed large-eddy simulations (LESs) to investigate the parameter dependence of the MLD and suggested that the MLD is proportional to

$$
L_{Z 72}=\frac{u_{*}^{2}}{\sqrt{B_{f} f}} .
$$

This length scale was first proposed by Zilitinkevich (1972) for the stabilized atmospheric boundary layer thickness. Later studies (Zilitinkevich et al. 2002, 2007) extended the scale to cover the thickness under weak stabilizing heat flux where the Ekman length scale $L_{\mathrm{EKD}}\left(=u_{*} / f\right)$ is the more relevant length scale. The extended scale is represented as

$$
L_{Z 02}=\left(\frac{c_{1}}{L_{\mathrm{EKD}}^{2}}+\frac{c_{2}}{L_{Z 72}^{2}}\right)^{-1 / 2},
$$

where $c_{1}$ and $c_{2}$ are empirical constants. From observed data and numerical simulations, Yoshikawa (2015) showed that the MLD in the ocean is also proportional to $L_{Z 02}$.

In these MLD scalings, the surface fluxes are assumed constant. Although numerical simulations by Goh and Noh (2013) and Yoshikawa (2015) were run under diurnally cycling surface heat flux, they did not consider the diurnal cycling effects. However, in most regions, the ocean surface layer is heated by solar radiation during the daytime while it is cooled by longwave radiation and turbulent heat fluxes during the nighttime. Recent studies (e.g., Guemas et al. 2013; Large and Caron 2015) showed that the diurnal cycle of the surface heat flux affects atmospheric circulations by increasing the daily mean SST by an order of $0.1 \mathrm{~K}$. This increase in the daily mean SST is caused by rectified vertical heat transfer due to diurnal cycling of the vertical mixing. Daytime heat gain is confined near the surface due to weak vertical mixing while nighttime heat loss is distributed over the MLD because of strong vertical mixing. Thus, the heat is trapped near the surface and the near surface temperature is increased even if the heat gain and the heat loss are equal in magnitude.

Recently, Bernie et al. (2005) showed that the diurnal cycle makes the MLD greater near the equator. Since the MLD controls SST changes through the heat capacity as mentioned above, this implies that the diurnal cycle may affect the SST by changing the MLD, as well as by rectifying the heat transfer. It remains, however, unclear how the diurnal cycle deepens the ML. Consequently, it remains unknown whether this deepening is limited to the equatorial region, and how substantial the SST change due to this MLD change really is.

In this study, we investigated the effects of the diurnal cycle of the surface heat (buoyancy) flux on the MLD and sea surface warming (SSW) in the heating season. The present study is intended to clarify the dynamics involved in the diurnal cycle effects and quantify its potential impacts on the SST, rather than to reproduce the realistic MLD distribution. To this aim, we used LESs which simulated shear-driven and convective turbulence with high accuracy. In section 2, the configuration of the numerical simulation (LES) is presented. Section 3 provides the results of the LESs, showing that the diurnal cycle changed the MLD and SSW compared to their values without the cycle. Most importantly, the diurnal cycle effect was opposite at lower and higher latitudes. The cycle made the MLD greater (shallower) and the SSW smaller (larger) at lower (higher) latitudes. In section 4, the mechanism of the latitudinal dependence of the diurnal cycle is discussed using a simple one-dimensional mixed layer model which reproduced LES results qualitatively (but not quantitatively, indicating the importance of LESs). The possible impacts of the diurnal cycle on the SSW were also evaluated using climatological data of the sea surface fluxes and scaling relations obtained from the LES results in section 4, before summarizing the present study in section 5 .

\section{Numerical model and experimental configurations}

The LES model used in the present study is similar to the model used in Yoshikawa (2015) and Ide and Yoshikawa (2016). The governing equations are the momentum equation, continuity equation, advectiondiffusion equation of buoyancy, and the tendency equation of kinetic energy at subgrid scale under the incompressible, $f$-plane, Boussinesq, and rigid-lid approximations,

$$
\begin{aligned}
\frac{\partial u_{i}}{\partial t}+\frac{\partial u_{i} u_{j}}{\partial x_{j}}+f \varepsilon_{i j 3} u_{j} & =-\frac{\partial}{\partial x_{i}} \frac{p}{\rho_{0}}+b \delta_{i 3}+\frac{\partial}{\partial x_{j}}\left(2 \nu s_{i j}\right), \\
\frac{\partial u_{j}}{\partial x_{j}} & =0 \\
\frac{\partial b}{\partial t}+\frac{\partial u_{j} b}{\partial x_{j}} & =\frac{\partial}{\partial x_{j}}\left(\kappa \frac{\partial b}{\partial x_{j}}\right)
\end{aligned}
$$




$$
\begin{gathered}
\frac{\partial e}{\partial t}+\frac{\partial u_{i} e}{\partial x_{i}}= \\
-2 \nu s_{i j} s_{i j}-\kappa \frac{\partial b}{\partial x_{i}} \delta_{i 3}+\frac{\partial}{\partial x_{i}}\left(2 \nu \frac{\partial e}{\partial x_{i}}\right) \\
-\frac{0.19+0.74 \Lambda / \Delta}{\Lambda} e^{3 / 2},
\end{gathered}
$$

where $x_{i}(i=1,2,3)$ denotes the Cartesian coordinates $(x, y, z)$ with $z$ pointing upward, $t$ is time, $u_{i}$ represents the velocity components $(u, v, w)$ in the $x_{i}$ direction, $p$ is pressure, $b \quad(=\alpha g \theta$, where $\alpha=$ $2.0 \times 10^{-4} \mathrm{~K}^{-1}$ is the thermal expansion coefficient of water, $g=9.8 \mathrm{~m} \mathrm{~s}^{-2}$ is acceleration due to gravity, and $\theta$ is temperature anomaly from a reference value) is buoyancy, $e$ is subgrid scale kinetic energy, and $s_{i j}=\left(\partial u_{i} / \partial x_{j}+\partial u_{j} / \partial x_{i}\right) / 2$ is the strain rate tensor. In the LES model, these variables are spatially filtered over the grid scale considered. Subgrid-scale parameterization followed the method described by Deardorff (1980). The eddy viscosity coefficient $\nu$ and the eddy diffusivity coefficient $\kappa$ are represented as

$$
\begin{aligned}
& \nu=0.1 \Lambda e^{1 / 2}, \quad \kappa=\left(1.0+2.0 \frac{\Lambda}{\Delta}\right) \nu, \quad \text { and } \\
& \Lambda=\left\{\begin{array}{cl}
\min \left[\Delta, 0.76 e^{1 / 2}(\partial b / \partial z)^{-1 / 2}\right] & \partial b / \partial z>0, \\
\Delta & \partial b / \partial z \leq 0,
\end{array}\right.
\end{aligned}
$$

where $\Delta$ is grid spacing described later.

In the present study, we considered a laterally periodic cubic ocean with momentum and buoyancy fluxes being imposed at the surface (Fig. 1),

$$
\begin{aligned}
\nu \frac{\partial u}{\partial z} & =u_{*}^{2}, \\
\nu \frac{\partial v}{\partial z} & =0, \quad \text { and } \\
\kappa \frac{\partial b}{\partial z} & =\frac{\alpha g}{\rho_{0} C_{s}} H_{f}(t)=B_{f}(t),
\end{aligned}
$$

where $C_{s}\left(=4.0 \times 10^{3} \mathrm{~J} \mathrm{~kg}^{-1} \mathrm{~K}^{-1}\right)$ and $H_{f}$ denote the heat capacity of water and the surface heat flux, respectively. We also imposed flux of subgrid-scale kinetic energy induced by wave breaking and subgridscale shear production at the surface,

$$
\begin{gathered}
2 \nu \frac{\partial e}{\partial z}=m u_{*}^{3}, \\
2 \nu s_{i j} s_{i j}=\frac{u_{*}^{3}}{k z_{0}} \psi,
\end{gathered}
$$

where $z_{0}\left(=3.0 \times 10^{5} u_{*}^{2} / g\right)$ is roughness length of the sea surface, $k(=0.4)$ is the von Kármán constant, and (a)

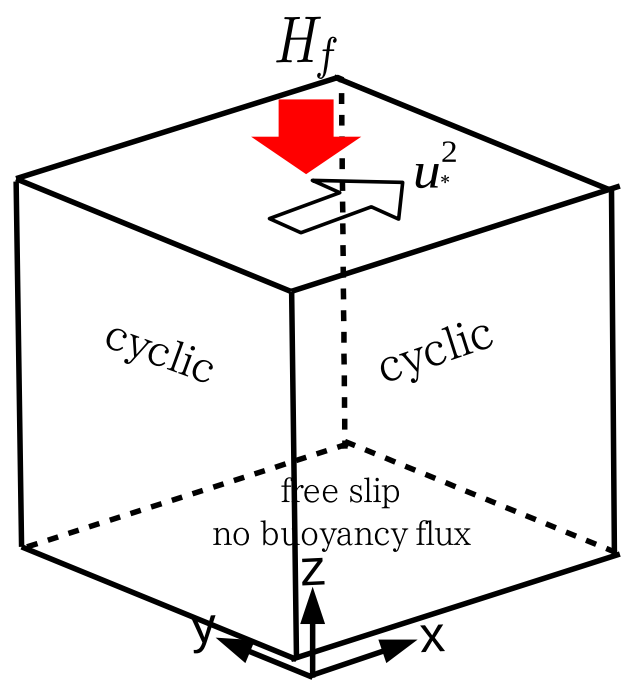

(b)

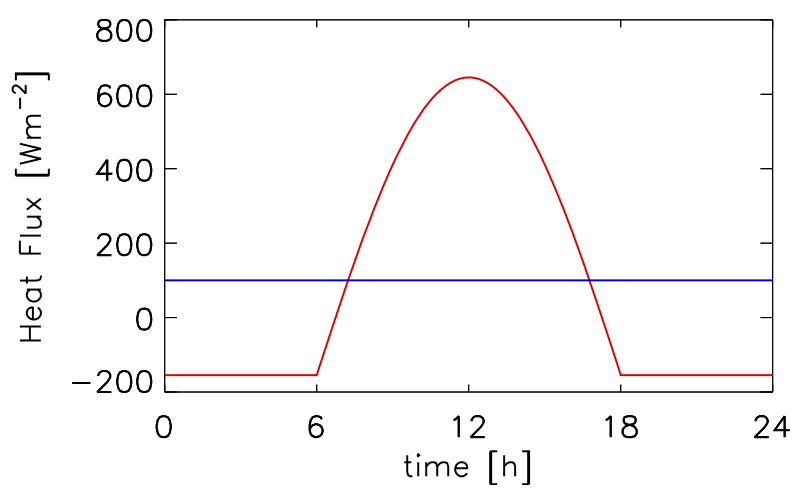

FIG. 1. (a) Schematic view of the modeled ocean. (b) Imposed surface heat flux in the DM (blue line) and DC (red line) experiments $\left(H_{f 0}=100 \mathrm{~W} \mathrm{~m}^{-2}, H_{A}=800 \mathrm{~W} \mathrm{~m}^{-2}, T_{h}=12 \mathrm{~h}\right)$.

the value of $m$ was 40 (e.g., Noh et al. 2004). In the above, $\psi$ is represented as (Businger et al. 1971)

$$
\psi=\left\{\begin{array}{cl}
1+4.7 z_{0} / L_{\mathrm{MOL}} & \partial b / \partial z \geq 0, \\
\left(1-15 z_{0} / L_{\mathrm{MOL}}\right)^{-1 / 4} & \partial b / \partial z<0,
\end{array}\right.
$$

where $L_{\mathrm{MOL}}\left(=u_{*}^{3} / k B_{f}\right)$ is the Monin-Obukhov length. At the bottom, the free slip condition and no-buoyancy flux condition were imposed. The lateral boundaries were periodic in both directions. Initially, the buoyancy was uniform $(b=0$, which corresponds to $\theta=0)$ and the motion was at rest. In the following, the temperature anomaly $\theta$ is simply referred to as temperature.

It should be commented here on surface wave effects in our LESs. We performed several LESs with $m=0$ in Eq. (12) (no wave breaking) and found that the MLDs simulated with $m=0$ and $m=40$ were 
TABLE 1. Parameters used in the LESs (open circles) shown in Fig. 7b.

\begin{tabular}{lrccc}
\hline \hline & & \multicolumn{3}{c}{$H_{A}\left(\mathrm{~W} \mathrm{~m}^{-2}\right)$} \\
\cline { 3 - 5 } & & 400 & 800 & 1200 \\
\hline$T_{h}(\mathrm{~h})$ & 9 & & $\circ$ & \\
& 12 & $\circ$ & $\circ$ & $\circ$ \\
& 15 & & $\circ$ & \\
\hline
\end{tabular}

almost the same (not shown). We also performed several LESs with the vortex force in Eq. (3) and reproduced Langmuir circulations (LCs). It was found that LCs deepened the ML as in previous studies (e.g., McWilliams et al. 1997; Grant and Belcher 2009) but did not alter the diurnal cycle effects on the MLD described in the present study (not shown). This is consistent with Goh and Noh (2013) and Noh and Choi (2018) who reported that LCs do not alter latitudinal dependence of the MLD. Therefore, the effects of surface waves (wave breaking and LCs) were not discussed afterward, though the wave breaking effect was kept in our model $(m=40)$ because the
TABLE 2. Parameters used in the LESs (open circle) shown in Figs. 8 and 9.

\begin{tabular}{lcccc}
\hline \hline & & \multicolumn{3}{c}{$H_{f 0}\left(\mathrm{~W} \mathrm{~m}^{-2}\right)$} \\
\cline { 3 - 5 } & & 50 & 100 & 200 \\
\hline$u_{*}^{2}\left(\mathrm{~m}^{2} \mathrm{~s}^{-2}\right)$ & $0.5 \times 10^{-4}$ & & $\circ$ & \\
& $1.0 \times 10^{-4}$ & $\circ$ & $\circ$ & $\circ$ \\
& $2.0 \times 10^{-4}$ & & $\circ$ & \\
\hline
\end{tabular}

properties of near the surface can be well reproduced with wave breaking (e.g., Noh et al. 2009) whose effects on near-surface turbulence were reported significant even when the LC effects were not significant (Gerbi et al. 2009).

In this study, a pair of experiments were performed: one with the diurnal cycle of the surface heat flux (hereafter referred to as the DC experiment) and the other without the cycle (i.e., with constant surface heat flux, hereafter referred to as the DM experiment). In the DM experiment, $H_{f}(t)$ was constant $\left[H_{f}(t)=H_{f 0}\right]$, while in the DC experiment, $H_{f}(t)$ changes diurnally as

$$
H_{f}(t)=\left\{\begin{array}{cc}
H_{A}\left\{\sin \left[\frac{t-\left(12-T_{h} / 2\right)}{T_{h}} \pi\right]-\frac{T_{h}}{12 \pi}\right\}+H_{f 0} & 12-\frac{T_{h}}{2}<\bmod (t, 24)<12+\frac{T_{h}}{2}, \\
-H_{A} \frac{T_{h}}{12 \pi}+H_{f 0} & \text { otherwise }
\end{array}\right.
$$

Note that the daily mean value of $H_{f}(t)$ in the DC experiment was equal to $H_{f 0}$, the heat flux in the DM experiment. Figure $1 \mathrm{~b}$ shows the heat fluxes for both the DM and DC experiments. The diurnal cycle in the present study was specified by the heat flux amplitude $H_{A}$ and the heating time duration $T_{h}$. Several $H_{A}$ and $T_{h}$ (Table 1 ) were tested (section $3 \mathrm{~b}$ ). However, unless otherwise specified, $H_{A}=800 \mathrm{~W} \mathrm{~m}^{-2}$ and $T_{h}=$ $12 \mathrm{~h}$ were used.

The governing equations were discretized using the second-order finite-difference scheme and integrated using the second-order Runge-Kutta scheme. The number of grid cells was 128 in each $x_{i}(i=1,2,3)$ direction. The grid spacing $\Delta$ was uniform in each experiment but changed among experiments according to a value of $L_{Z 72}\left(=u_{*}^{2} / \sqrt{B_{f 0} f}\right.$, where $B_{f 0}=$ $\left.\alpha g / \rho_{0} C_{s} H_{f 0}\right)$ calculated from the imposed parameters $\left(u_{*}, B_{f 0}, f\right) ; \Delta=0.5 \mathrm{~m}, 1.0 \mathrm{~m}, 2.0 \mathrm{~m}$ for $L_{Z 72}<32 \mathrm{~m}$, $32 \mathrm{~m}<L_{Z 72}<128 \mathrm{~m}$, and $128 \mathrm{~m}<L_{Z 72}$, respectively. We performed several LESs with half grid spacing and found that these results were qualitatively similar to those with the original grid spacing (not shown). Thus, the present grid spacing is sufficient for the present purpose. The integration was continued for 15 days, by which time vertical mixing in the ML becomes statistically steady. The simulations were run with several values of momentum $\left(u_{*}^{2}\right)$ and surface heat $\left(H_{f 0}\right)$ flux (Table 2). To clarify the latitudinal dependence of the MLD and SSW, a series of experiments with several Coriolis parameters $(f=1.25,2.50,3.75,5.00,6.25,7.50$, $10.0,12.5 \times 10^{-5} \mathrm{~s}^{-1}$ ) were performed for each pair of $u_{*}$ and $H_{f 0}$. The inertial subrange in the kinetic energy spectrum was clearly identified in the ML (not shown), indicating good performance of the present LESs.

\section{Diurnal cycle effects of the surface heat flux on ML turbulence, MLD, and SSW}

\section{a. Time development of $M L$ in a standard case}

Initially, we investigated the ML development in the experiments for $u_{*}^{2}=1.0 \times 10^{-4} \mathrm{~m}^{2} \mathrm{~s}^{-2}$ and $H_{f 0}=$ $100 \mathrm{~W} \mathrm{~m}^{-2}$ (hereafter referred to as a standard case). Figure 2 shows the time series of the horizontally averaged turbulence kinetic energy (TKE), its source and sink terms (as below), 


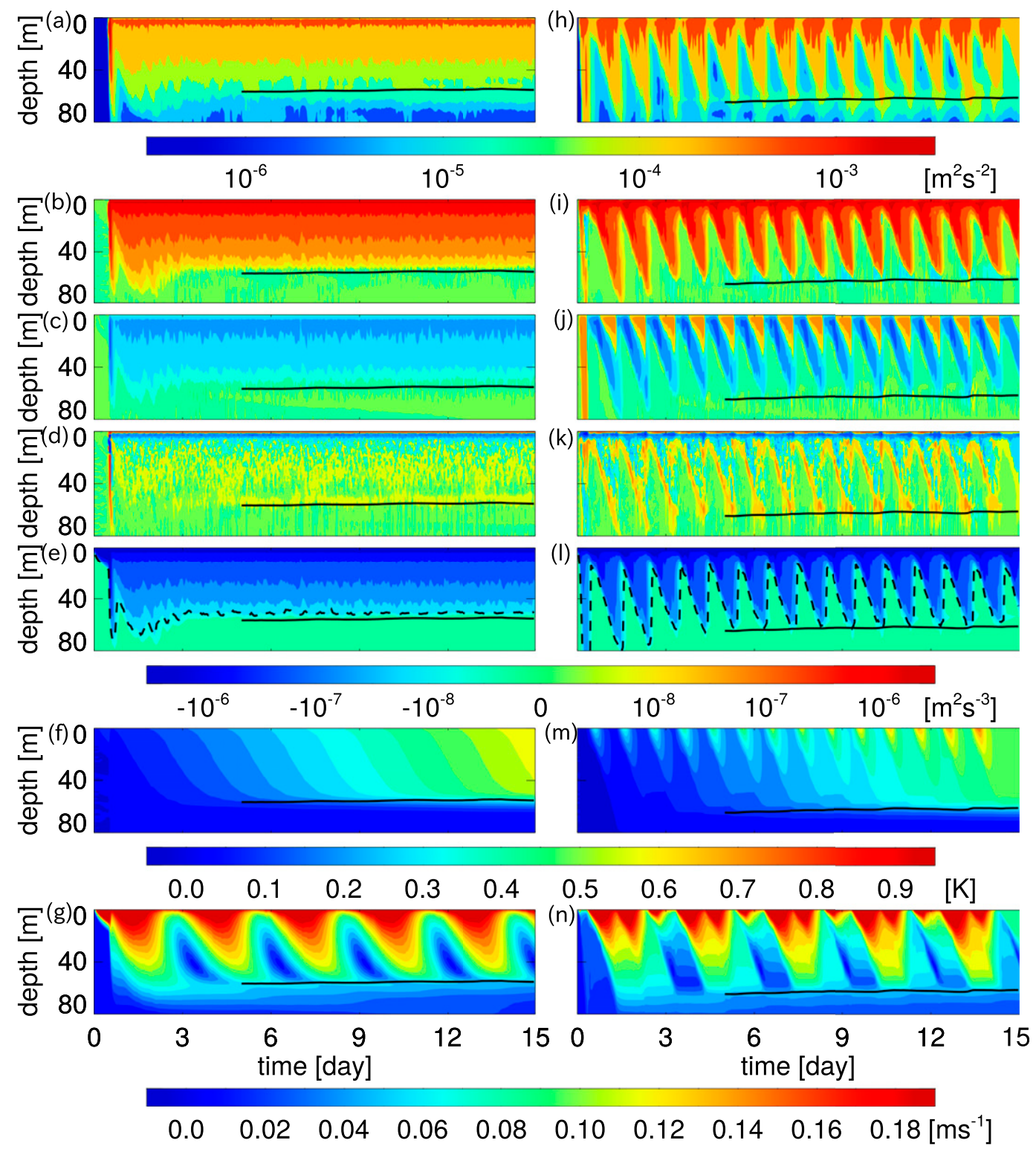

FIG. 2. Time-depth variation of the horizontally averaged (a),(h) TKE; (b),(i) SPR; (c),(j) BPR; (d),(k) DVT; (e),(l) DSP; (f),(m) temperature; and (g),(n) velocity magnitude in the (left) DM and (right) DC experiments of the lowerlatitude $\left(f=2.5 \times 10^{-5} \mathrm{~s}^{-1}\right)$ standard case. Solid lines represent the MLD, and dashed lines in (e) and (l) are the XLD.

$$
\frac{\partial}{\partial t}\left(\frac{1}{2} \overline{u_{k}^{\prime} u_{k}^{\prime}}\right)=\underbrace{-\overline{u_{k}^{\prime} w^{\prime}} \frac{\partial \overline{u_{k}}}{\partial z}}_{\text {SPR }} \underbrace{+\overline{w^{\prime} b^{\prime}}}_{\text {BPR }} \underbrace{-\frac{\partial}{\partial z}\left(\frac{1}{2} \overline{u_{k}^{\prime} u_{k}^{\prime} w^{\prime}}+\frac{\overline{p^{\prime} w^{\prime}}}{\rho_{0}}\right)}_{\text {DVT }} \underbrace{+\varepsilon}_{\text {DSP }}+\text { SGS, }
$$

temperature, and velocity profiles in the standard $\mathrm{DM}$ and DC experiments at lower latitude $(f=2.5 \times$ $10^{-5} \mathrm{~s}^{-1}$, corresponding to $\left.10^{\circ} \mathrm{N}\right)$. Here, the prime means the anomaly from the horizontal mean value, and the overbar represents the horizontal average. The TKE was defined as $\overline{u_{k}^{\prime} u_{k}^{\prime} / 2}$, while SPR, BPR, DVT, and DSP represent a rate of the shear production, buoyancy production, divergence of vertical transport due to advection and pressure work, and dissipation of the TKE, respectively. The dissipation rate was given by the last term on the right-hand side of Eq. (6). The contribution from the other subgrid-scale turbulence 
was represented by SGS, which was much smaller than those from SPR, BPR, and DVT except very near the surface and below the ML. In the DM experiment (Figs. 2a-g), a layer of the larger TKE deepened at first and then shoaled for the first three days of the experiment (Fig. 2a). In this layer, the shear production and dissipation were dominant; both the buoyancy production (which was negative) and divergence of vertical transport were one order smaller (Figs. 2b-e). Strong mixing transported high temperature and large velocity downward to the base of this layer (Figs. 2f,g). After day 3, the production and dissipation terms became statistically steady, and the deepening of this mixing layer (hereafter referred to as XL) ceased. In the present study, the XL was defined as a layer with a larger dissipation rate than $10^{-8} \mathrm{~m}^{2} \mathrm{~s}^{-3}$ (Sutherland et al. 2014). At the depth of the XL (XLD) $(\sim 50 \mathrm{~m})$, a thermocline was formed (Fig. 2f). Although turbulence in the XL became statistically steady, the XL temperature kept increasing due to the (constant) surface heating.

In the DC experiment (Figs. $2 \mathrm{~h}-\mathrm{n}$ ), on the other hand, the daytime surface heating and the nighttime cooling caused a diurnal cycle in the TKE, in its source and sink terms, and in the XL temperature and velocity. The layer of the larger TKE, or the XL, was trapped near the surface during the daytime and deepened during the nighttime (Figs. 2h,l). As in the DM experiment, the shear production was the largest production term in the DC experiment (Fig. 2i). The buoyancy production, which was positive during the nighttime, regulated the diurnal variation of the TKE and mixing (Fig. 2j). The vertical transport made the TKE large near the base of the XL (Fig. 2k). The dissipation was nearly balanced with the shear production (Figs. 2i,l). The thermocline was formed at the greatest XLD ( $\sim 60 \mathrm{~m})$ (Fig. $2 \mathrm{~m}$ ). The temperature above the greatest XLD increased with time while varying diurnally.

To see the diurnal cycle effects on the mean temperature structure, the daily averaged temperature profiles on the last day (day 15) are shown in Fig. 3a. In the DM experiment, the imposed surface heat was distributed almost uniformly over the ML. In the DC experiment, on the other hand, more heat was trapped near the surface due to the rectified heat transfer mentioned in section 1. Note also that the base of the ML was deeper in the DC experiment than in the DM experiment. To quantify this difference in more detail, the MLD was defined as the depth at which the 24-hrunning-mean horizontally averaged temperature had the largest vertical gradient. At the end of the experiment, the MLD in the DM experiment $\left(L_{\mathrm{LES}}^{\mathrm{DM}}\right)$ was $55 \mathrm{~m}$, while the MLD in the DC experiment $\left(L_{\mathrm{LES}}^{\mathrm{DC}}\right)$ was $61 \mathrm{~m}$. The MLD in the DC experiment was greater by $10 \%$
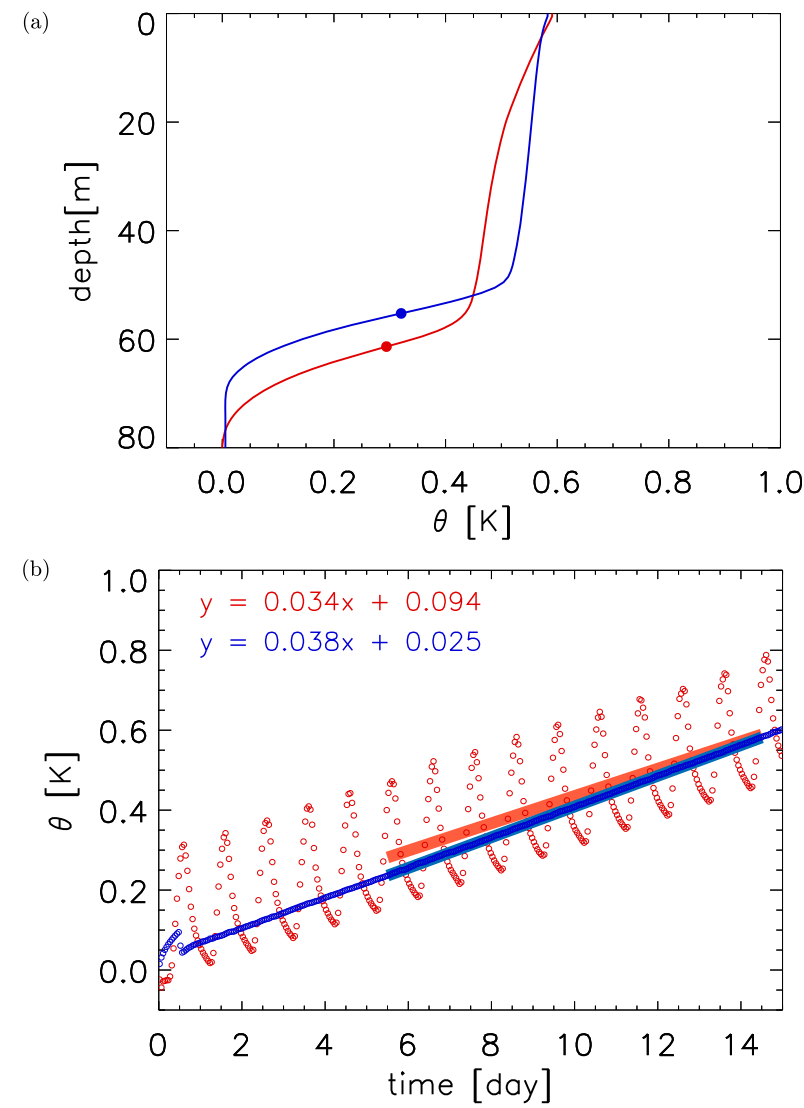

FIG. 3. (a) Horizontally averaged daily mean temperature profiles on day 15 in the DM (blue line) and DC (red line) experiments of the lower-latitude standard case. Solid circle represents the MLD. (b) Time series of the horizontally averaged SST in the DM (blue circle) and DC (red circle) experiments of the lower-latitude standard case. Solid lines are the regression lines of the daily averaged SST after day 5 .

(6m) than that in the DM experiment. Thus, the diurnal cycle deepened the ML at this lower latitude. This result is consistent with Bernie et al. (2005).

Figure $3 b$ shows the time series of the horizontally averaged SST in both the DM and DC experiments. The SST in the DM experiment increased at a constant rate, while the SST in the DC experiment increased with the diurnal cycle. The amplitude of the diurnal temperature cycle changed little with time. The daily mean SST was higher in the DC experiment than in the DM experiment for day 5-15. This was due to the rectified vertical heat transfer. Note, however, that the SSW rate was $0.034 \mathrm{Kday}^{-1}$ in the DC experiment, which was $10 \%$ smaller than that of the DM experiment $\left(0.038 \mathrm{~K} \mathrm{day}^{-1}\right)$. Due to this reduced warming rate, the daily mean SST in the DM and DC experiments became nearly the same on day 15 , and the former became larger than the latter after day 15 (not shown). Thus, the SST increase due to the rectification effect can be canceled by the decrease in the "SSW rate" by the diurnal cycle. 


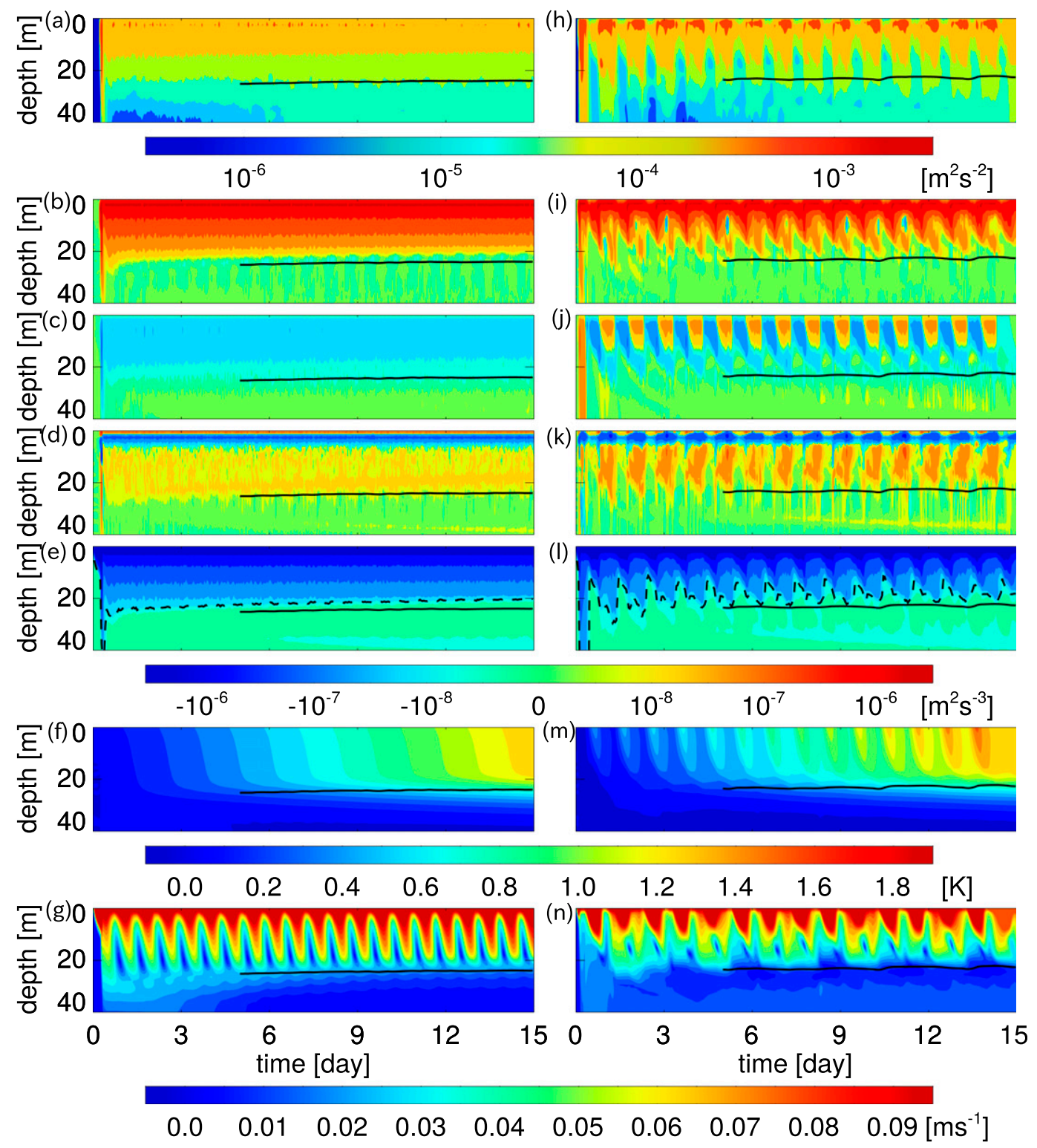

FIG. 4. As in Fig. 2, but for the higher-latitude $\left(f=1.0 \times 10^{-4} \mathrm{~s}^{-1}\right)$ standard case.

The SSW rate difference between the DM and DC experiments can be explained by the MLD difference. Given that the heat imposed at the surface was distributed uniformly over the ML, the temporal variation of the horizontally averaged daily mean ML temperature $\langle\bar{\theta}\rangle$ was represented as

$$
\frac{\partial\langle\bar{\theta}\rangle}{\partial t} \cong-\frac{\partial}{\partial z}\left\langle\overline{\left\langle w^{\prime} \theta^{\prime}\right.}\right\rangle \cong \frac{H_{f 0}}{\rho C_{s} L_{\mathrm{LES}}},
$$

where the bracket represents the daily average. In the above, the SSW rate $(\partial\langle\bar{\theta}\rangle / \partial t)$ was inversely proportional to the $\operatorname{MLD}\left(L_{\mathrm{LES}}\right)$. Since $L_{\mathrm{LES}}^{\mathrm{DC}} / L_{\mathrm{LES}}^{\mathrm{DM}}=61 / 55=1.1$, the difference between the SSW rates in the DM and DC experiments was estimated as $\left(\partial\left\langle\overline{\theta^{\mathrm{DM}}}\right\rangle / \partial t\right) /\left(\partial\left\langle\overline{\theta^{\mathrm{DC}}}\right\rangle / \partial t\right) \cong$ $\left(L_{\mathrm{LES}}^{\mathrm{DM}} / L_{\mathrm{LES}}^{\mathrm{DC}}\right)^{-1}=1.1$. This value was consistent with the observed value of the SSW ratio $(0.038 / 0.034=1.1)$. Thus, in the lower-latitude standard case, the ML deepening due to the diurnal cycle reduced the SSW rate and hence the SST increase.

It is instructive to see the results of a higher-latitude $\left(f=1.0 \times 10^{-4} \mathrm{~s}^{-1}\right.$, corresponding to $\left.40^{\circ} \mathrm{N}\right)$ standard case. Figure 4 shows the TKE, its source and sink terms, temperature, and velocity profiles in the DM and DC experiments of the higher-latitude standard case. It was found that the overall features of the TKE, its source 
and sink terms, temperature, and velocity were similar to those of the lower-latitude case. However, a couple of differences were evident between the lowerand higher-latitude cases as described below. First, because of larger $f$, a statistically steady state was achieved earlier, and the MLs were shallower in the higher-latitude case than in the lower-latitude case in both the DM and DC experiments (Figs. 2, 4). Larger $f$ effects can also be found in the temporal variations of the shear and buoyancy productions and the XLD in the DC experiment. The shear production in the lower-latitude case showed a V-shape pattern each day (Fig. 2i), while the shear production in the higherlatitude case had a second peak (more like a W-shape pattern, Fig. 4i). The buoyancy production also showed a different pattern between the lower- and higher-latitude cases; positive buoyancy production showed a $\mathrm{V}$-shape pattern in the lower-latitude case (Fig. 2j) while it showed more like a U-shape pattern in the higher-latitude case (Fig. 4j). The divergence of vertical transport was larger in the higher-latitude case than in the lower-latitude case (Figs. 2k, 4k). More noteworthy is that the MLD, corresponding to the largest XLD, was smaller in the DC experiment than in the DM experiment in the higherlatitude case (Fig. 5a). According to this smaller MLD, the SSW rate in the DC experiment was higher than that in the DM experiment in the higher-latitude case (Fig. 5b). This is in marked contrast to the lowerlatitude case (Fig. 3). The daily mean SST was higher in the DC experiment than in the DM experiment for day 5-15 (Fig. 5b) as in the lower-latitude case, but the SST difference between the DM and DC experiments became larger over time. This is because the SSW rate in the DC experiment was higher due to the smaller MLD than in the DM experiment at this higher latitude.

To see more detailed differences between the lowerand higher-latitude cases of the DC experiment, diurnal variations in the shear production, buoyancy production, and divergence of vertical transport as well as the vertical shear of horizontal velocity $\left[S^{2}=(\partial \bar{u} / \partial z)^{2}+\right.$ $\left.(\partial \bar{v} / \partial z)^{2}\right]$, buoyancy stratification $\left(N^{2}=\partial \bar{b} / \partial z\right)$, and the Richardson number $\left(\mathrm{Ri}_{g}=N^{2} / S^{2}\right)$ were averaged for the last 10 days and are shown in Fig. 6. (Note that the averaged diurnal cycle was repeated twice in Fig. 6.) In the lower-latitude case, the shear production was always large in the XL (Fig. 6a). Buoyancy production, which was one order smaller than the shear production, was positive (negative) in the upper (lower) XL during the nighttime (Fig. 6b). Note that this corresponds to reducing buoyancy stratification (Fig. 6e). The divergence of vertical transport was (a)

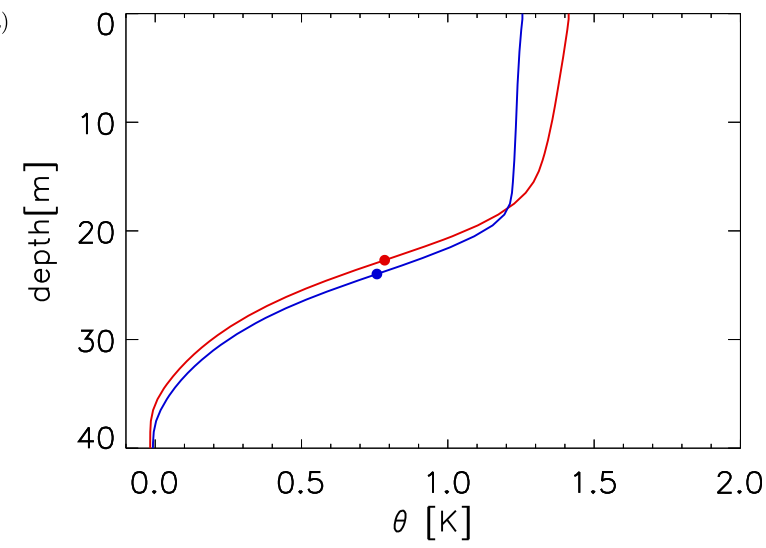

(b)

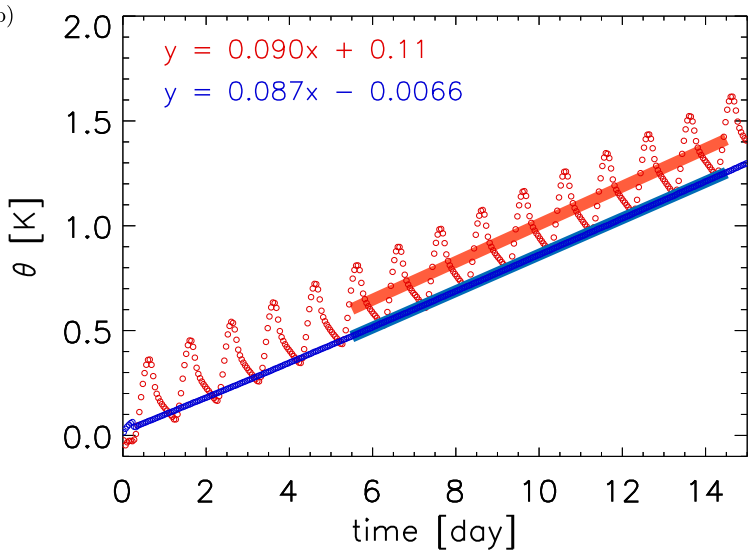

FIG. 5. As in Fig. 3, but for the higher-latitude $\left(f=1.0 \times 10^{-4} \mathrm{~s}^{-1}\right)$ standard case.

small (Fig. 6c). Thus, shear-driven turbulence played a major role in the XL deepening, and the XL deepening followed the shear production deepening during the nighttime (Fig. 6a). Note, however, that convective turbulence also contributed to the XL deepening indirectly by reducing buoyancy stratification (and Richardson number) which made the shear instability to develop more easily. In the higher-latitude case, on the other hand, the shear production was small during the nighttime (Fig. 6g), but the reduced buoyancy stratification contributed to decreasing the Richardson number at around the XL base (Figs. 6k,1). In addition, the divergence of vertical transport was as large as the shear production in the lower XL (Figs. 6g,i). The vertical transport, which transported high TKE near the surface to the lower XL, seems to be associated mainly with convective motion. The XL deepening corresponded well with both the deepening of the shear production and the divergence of vertical transport (Figs. 6g,i). Thus, convection contributed to the XL deepening not only through reducing buoyancy stratification but also by transporting TKE to the XL base. These features in the higher-latitude case 
(a)

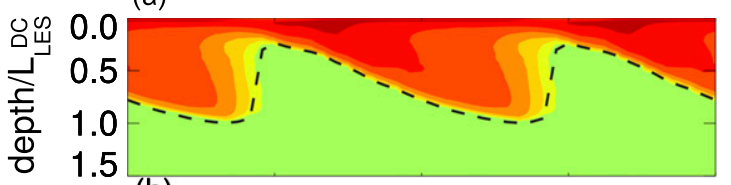

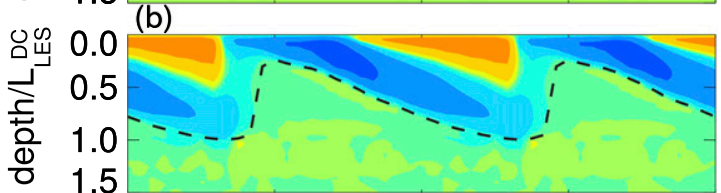

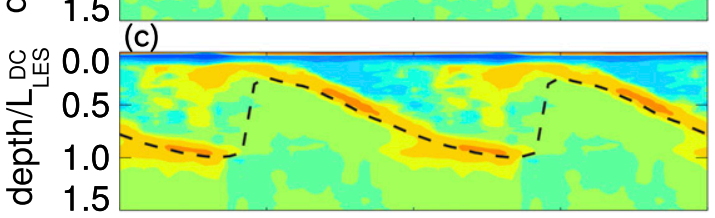

(g)

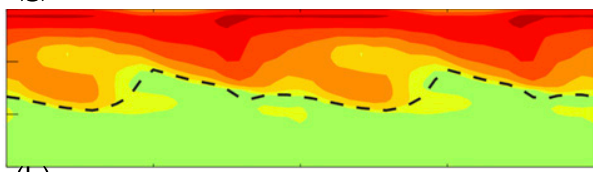

(h)

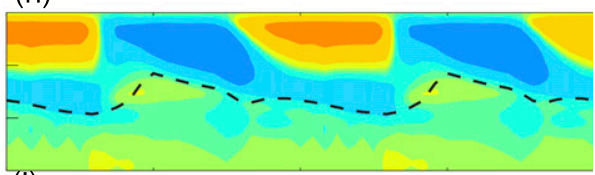

(i)

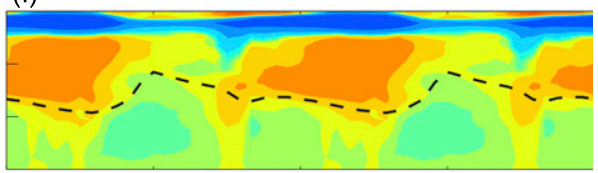

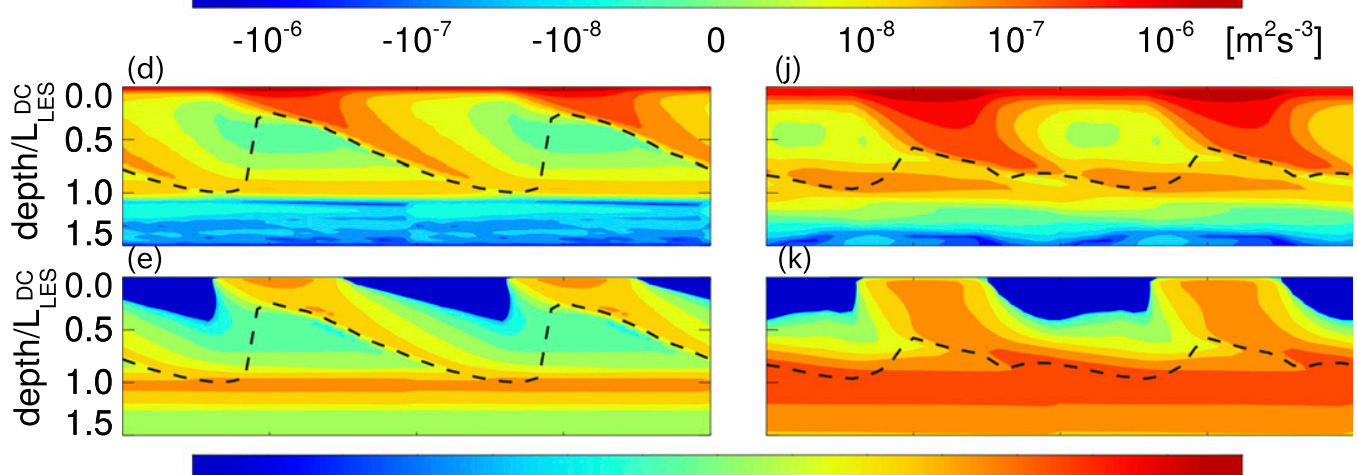

(f)

$\begin{array}{llll}0 & 10^{-8} & 10^{-7} & 10^{-6}\end{array}$

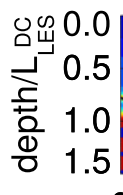

(i)

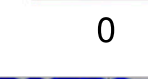

(I) $10^{-5}$
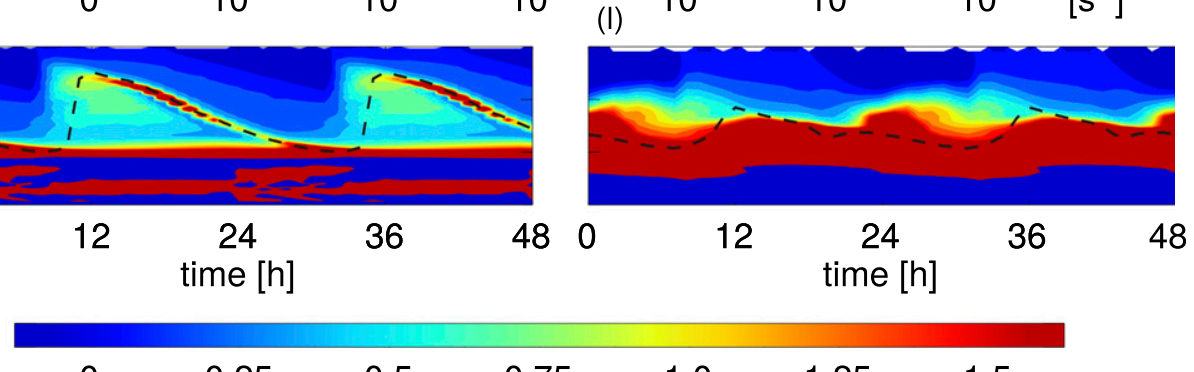

\section{0}

0.25

\section{5}

0.75

1.0

1.25

1.5

FIG. 6. Averaged diurnal variations in (a),(g) SPR; (b),(h) BPR; (c),(i) DVT; (d),(j) magnitude of vertical shear of the horizontal velocity; (e),(k) buoyancy stratification; and (f),(l) Richardson number in the (left) lower- and (right) higher-latitude cases of the standard DC experiments. The average was taken for day 5-15. The horizontal axis is time (averaged diurnal cycles are repeated twice), and the vertical axis is depth normalized by $L_{\mathrm{LES}}^{\mathrm{DC}}$. Dashed lines represent the XLD.

(Figs. 6g-1) were in marked contrast to those in the lower-latitude case (Figs. 6a-f)

\section{b. Parameter dependence of $M L D$ and SSW rate}

Results in the previous subsection showed that the diurnal cycle effects on the MLD and SSW rate were opposite at lower $\left(10^{\circ} \mathrm{N}\right)$ and higher $\left(40^{\circ} \mathrm{N}\right)$ latitudes. To reveal the latitudinal dependence of the diurnal cycle effects in more detail, we examined the MLDs simulated with several Coriolis parameters $f$ for $u_{*}^{2}=1.0 \times 10^{-4} \mathrm{~m}^{2} \mathrm{~s}^{-2}$ and $H_{f 0}=100 \mathrm{~W} \mathrm{~m}^{-2}$ (standard case) and show the result in Fig. 7. At lower latitudes, the MLDs were larger in the DC experiments than in the DM experiments while at higher latitudes, they were smaller in the DC experiments than in the DM experiments (Fig. 7a). It was found that the MLDs in the DM experiments depended almost linearly on $f$ over the latitudes investigated in the present study. In the DC experiments, on the other hand, the MLDs showed different dependence on $f$. The dependence 

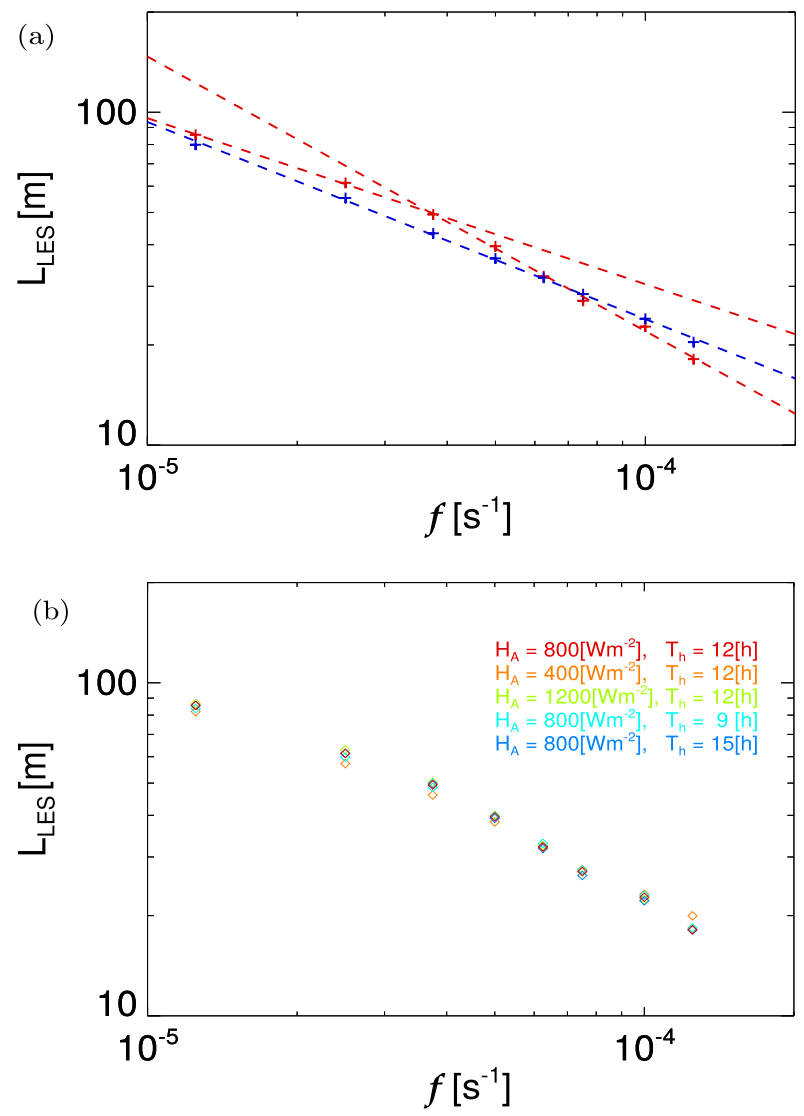

FIG. 7. (a) Latitudinal dependence of the MLD in the DM (blue) and DC (red) experiments for the standard case. The dashed lines represent the regression line. Note that the regression lines in the DC experiment were separately estimated at smaller and larger $f$ than $3.75 \times 10^{-5} \mathrm{~s}^{-1}$. (b) As in (a), but for the result in the nonstandard experiments with $H_{A}$ and $T_{h}$ listed in Table 1.

at lower latitudes $\left(f \leqq 4 \times 10^{-5} \mathrm{~s}^{-1}\right)$ was weak and similar to the DM experiments, but the dependence at higher latitudes $\left(f \geq 4 \times 10^{-5} \mathrm{~s}^{-1}\right)$ depended more on $f$. The reason for this latitudinal dependence is discussed in section $4 \mathrm{a}$.

It should also be noted how the latitudinal dependence of the MLD in the DC experiments changed with the diurnal amplitude of the surface heat flux $H_{A}$ and the heating time duration $T_{h}$. Figure $7 \mathrm{~b}$ shows the observed dependence of the MLD on $f$ for the experiments with $H_{A}$ and $T_{h}$ in Table 1 . Although the MLDs with small amplitude of surface heat flux $\left(H_{A}=400 \mathrm{~W} \mathrm{~m}^{-2}\right)$ approached the MLDs in the DM experiments, the latitudinal dependence of the MLD in the DC experiments did not greatly change with the diurnal amplitude of the surface heat flux $H_{A}$ and the heating time duration $T_{h}$.

To reveal the latitudinal dependence of the MLD for other momentum flux $u_{*}^{2}$ and heat flux $H_{f 0}$ values, we (a)

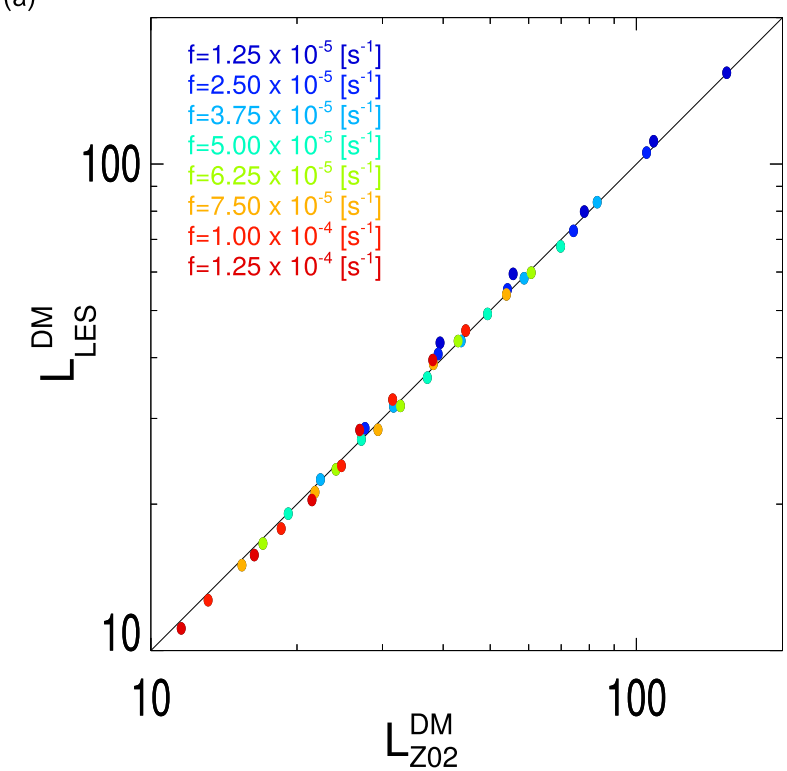

(b)

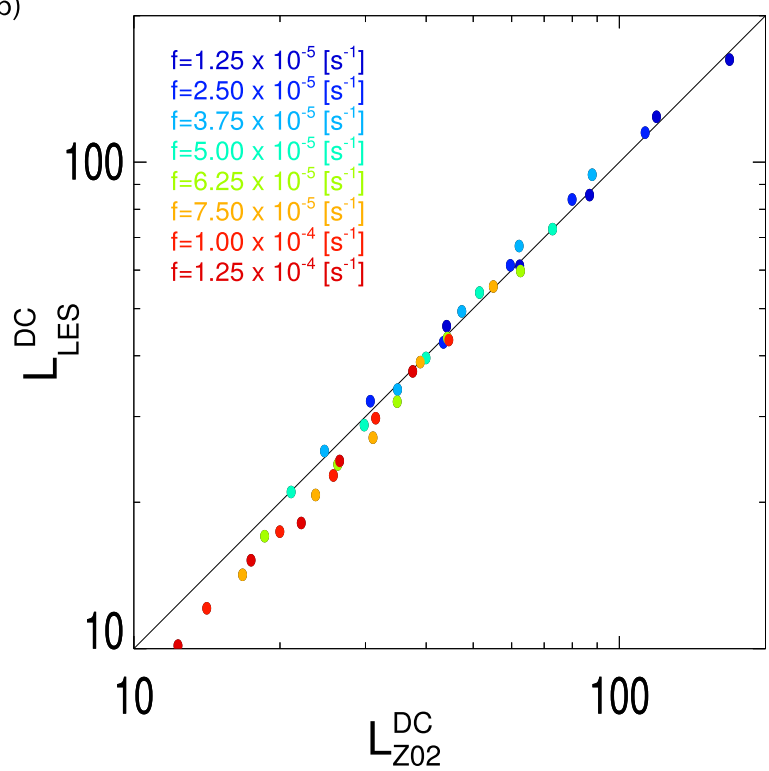

FIG. 8. Scatterplots between (a) $L_{Z 02}^{\mathrm{DM}}$ [Eq. (18), the best fitted MLD scale for the DM experiment] and $L_{\mathrm{LES}}^{\mathrm{DM}}$ (simulated MLD in the DM experiments) and between (b) $L_{Z 02}^{\mathrm{DC}}$ [Eq. (19), the best fitted MLD scale for the DC experiment] and $L_{\mathrm{LES}}^{\mathrm{DC}}$ (simulated MLD in the DC experiments). Color represents the latitudes.

also performed numerical simulations with the parameters shown in Table 2. According to previous studies (Zilitinkevich et al. 2002; Yoshikawa 2015), the MLD should be proportional to $L_{Z 02}$ [Eq. (2)], so we compared the MLDs in the DM and DC experiments with $L_{Z 02}$. Figure 8 shows scatterplots between $L_{Z 02}$ and $L_{\mathrm{LES}}^{\mathrm{DM}}$ and between $L_{Z 02}$ and $L_{\mathrm{LES}}^{\mathrm{DC}}$. Here, empirical parameters in $L_{Z 02}\left[c_{1}\right.$ and $c_{2}$ in Eq. (2)] were determined by the 
least squares fitting. In the DM experiment, the $L_{Z 02}$ that fits best the MLD $\left(L_{Z 02}^{\mathrm{DM}}\right)$ was

$$
L_{Z 02}^{\mathrm{DM}}=\left(\frac{3.8}{L_{\mathrm{EKD}}^{2}}+\frac{2.5}{L_{Z 72}^{2}}\right)^{-1 / 2},
$$

and in the DC experiments, the corresponding $L_{Z 02}$ $\left(L_{Z 02}^{\mathrm{DC}}\right)$ was

$$
L_{Z 02}^{\mathrm{DC}}=\left(\frac{5.1}{L_{\mathrm{EKD}}^{2}}+\frac{2.0}{L_{Z 72}^{2}}\right)^{-1 / 2} .
$$

The agreement between $L_{Z 02}^{\mathrm{DM}}$ and $L_{\mathrm{LES}}^{\mathrm{DM}}$ was good. However, there was clear and systematic deviation between $L_{Z 02}^{\mathrm{DC}}$ and $L_{\mathrm{LES}}^{\mathrm{DC}}$, especially at higher latitudes. This implies that the MLD in the DC experiment cannot be scaled by $L_{Z 02}$. In other words, the MLD under the diurnal cycle effects apparently depends on another parameter that is not included in Eq. (2). Figure 9a shows the latitudinal dependence of $L_{\mathrm{LES}}$ values in the DM and DC experiments. Here, $L_{\mathrm{LES}}$ and the Coriolis parameter $f$ were normalized by $L_{Z 02}^{\mathrm{DM}}$ [Eq. (18)] and $T_{24}(=24 \mathrm{~h})$, respectively. Over the entire range of $f$ investigated in the present study, $L_{\mathrm{LES}}^{\mathrm{DM}}$ was well scaled by $L_{Z 02}^{\mathrm{DM}}$. In contrast, $L_{\mathrm{LES}}^{\mathrm{DC}}$ systematically deviated from $L_{\mathrm{LES}}^{\mathrm{DM}}$ at higher latitudes than $f T_{24} / 2 \pi \cong 0.5\left(f \cong 4 \times 10^{-5} \mathrm{~s}^{-1}\right)$ where $L_{\mathrm{LES}}^{\mathrm{DC}} / L_{Z 02}^{\mathrm{DM}} \mathrm{de}-$ creased linearly with $f T_{24} / 2 \pi$. The $L_{\mathrm{LES}}^{\mathrm{DC}}$ was larger at low latitudes and smaller at high latitudes than $L_{Z 02}^{\mathrm{DM}}$ by $\leq 10 \%$.

The SSW rate was also systematically influenced by the diurnal cycle because the rate depends on the MLD through Eq. (17). Figure $9 b$ shows the SSW rates normalized by $H_{f 0} / \rho C_{s} L_{Z 02}^{\mathrm{DM}}$. Though the normalized SSW rate in the DM experiment did not significantly vary with $f$, the rate in the DC experiment changed less and more with $f$ at lower and higher latitudes, respectively.

\section{Discussion}

\section{a. Bulk model approach to understand the latitudinal dependence of $M L D$}

The previous section (section 3a) showed that turbulence was primarily shear driven, although the nighttime cooling seemed to be the key to change in the latitudinal dependence of the MLD in the DC experiment. To better understand how the shear-driven turbulence was modified by the nighttime cooling, we used a onedimensional bulk mixed layer model. For this aim, the horizontally averaged momentum and buoyancy advection-diffusion equations, (a)
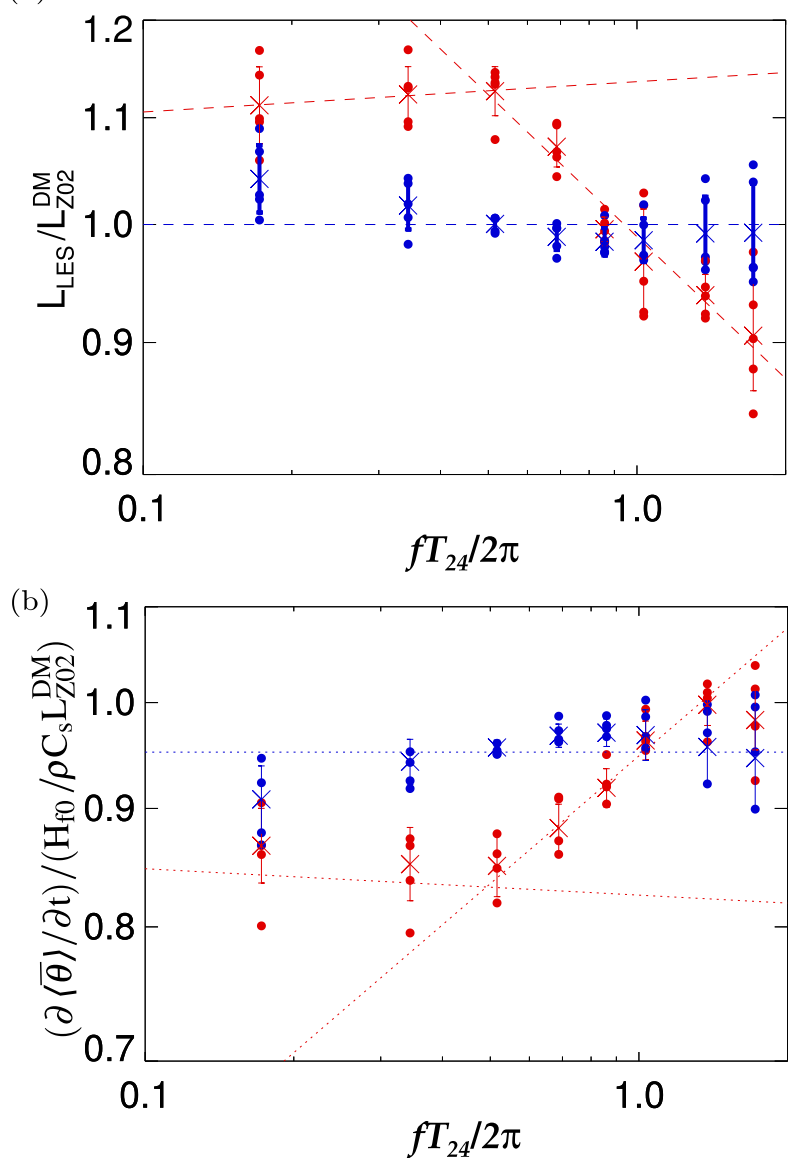

FIG. 9. Latitudinal dependence of the (a) MLD and (b) SSW rate in the DM (blue) and DC (red) experiments. The MLD and SSW rate were normalized by $L_{Z 02}^{\mathrm{DM}}$ and $H_{f 0} / \rho C_{s} L_{Z 02}^{\mathrm{DM}}$, respectively. Solid circles represent LES results, and the crosses and vertical bars represent the average and standard deviation of LES results at the same latitude $\left(f T_{24} / 2 \pi\right)$, respectively. Dashed lines represent regression lines.

$$
\begin{aligned}
\frac{\partial \bar{u}}{\partial t}-f \bar{v} & =\frac{\partial}{\partial z}\left(\nu_{T} \frac{\partial \bar{u}}{\partial z}\right), \\
\frac{\partial \bar{v}}{\partial t}+f \bar{u} & =\frac{\partial}{\partial z}\left(\nu_{T} \frac{\partial \bar{v}}{\partial z}\right), \quad \text { and } \\
\frac{\partial \bar{b}}{\partial t} & =\frac{\partial}{\partial z}\left(\kappa_{T} \frac{\partial \bar{b}}{\partial z}\right),
\end{aligned}
$$

were considered. In this section, $u, v$, and $b$ are not filtered but total variables. The eddy viscosity $\nu_{T}$ and eddy diffusivity $\kappa_{T}$ in these equations include the contribution from turbulence (which is explicitly simulated in LES) and are different from $\nu$ and $\kappa$ in the LES. Note that the effect of reducing stratification by convection is included in this model but the effect of TKE vertical transport by convection is not. 


\section{1) SCALing BASED ON AN ANALYTICAL APPROXIMATE SOLUTION}

Here, following Pollard et al. (1972), we assumed that the velocity and buoyancy are forced only by surface fluxes (i.e., damping of the inertial oscillations was not considered), that the velocity and buoyancy are vertically uniform in the XL due to strong turbulent mixing (large $\nu_{T}$ and $\kappa_{T}$ ) within the $\mathrm{XL}$, and that the mixing is determined by the bulk Richardson number

$$
\mathrm{Ri}_{b}=\frac{D \Delta b}{\Delta u^{2}+\Delta v^{2}},
$$

where $D$ is the XLD, $\Delta b$ is buoyancy anomaly, and $\Delta u$ and $\Delta v$ are velocity anomalies forced by the surface fluxes. In this subsection, the greatest XLD $\left(D^{\mathrm{MAX}}\right)$ was assumed to coincide with the MLD. Mixing takes place at the base of the XL to deepen the XL if $\mathrm{Ri}_{b}$ becomes lower than a certain critical value $\mathrm{Ri}_{b c}$. Under these assumptions, temporal evolution of the velocity and buoyancy anomalies are given by

$$
\begin{aligned}
\frac{\partial \Delta u D}{\partial t}-f \Delta v D & =u_{*}^{2}, \\
\frac{\partial \Delta v D}{\partial t}+f \Delta u D & =0, \quad \text { and } \\
\frac{\partial \Delta b D}{\partial t} & =B_{f} .
\end{aligned}
$$

Note that the MLD is limited by Earth's rotation $f$ rather than buoyancy stratification $\Delta b$ under a weak stabilizing buoyancy flux (Zilitinkevich et al. 2002; Yoshikawa 2015). However, this effect cannot be expressed in the above bulk model. Therefore, the present discussion is limited to the condition of a strong stabilizing buoyancy flux where the appropriate MLD scale is $L_{Z 02} \cong L_{Z 72}$, and focused on how the diurnal cycle changes the dependence on $f$ at $f \cong$ $4 \times 10^{-5} \mathrm{~s}^{-1}\left(f T_{24} / 2 \pi \cong 0.5\right)$.

First, the case of constant heat flux (DM experiment) was considered. In this case, the XL deepens due to increasing shear at first, but the growth of the shear ceases at about half the inertial period. The buoyancy stratification in the XL, on the other hand, increases due to constant heating. As a consequence, the Richardson number at the base of the XL increases and the XL deepening ceases after the inertial period. This discussion is described with the bulk model as below. The buoyancy anomaly increases with time as

$$
\Delta b=\frac{B_{f 0} t}{D} .
$$

The velocity anomalies become

$$
\Delta u=\frac{u_{*}^{2}}{f D} \sin f t, \quad \Delta v=-\frac{u_{*}^{2}}{f D}(1-\cos f t),
$$

thus

$$
\Delta u^{2}+\Delta v^{2}=\left[2 \frac{u_{*}^{2}}{f D} \sin \left(\frac{f t}{2}\right)\right]^{2} .
$$

For time significantly shorter than the inertial period $(t \ll 1 / f)$, the velocity anomaly magnitude develops with time as

$$
\Delta u^{2}+\Delta v^{2} \rightarrow\left(\frac{u_{*}^{2} t}{D}\right)^{2}
$$

so that the bulk Richardson number

$$
\mathrm{Ri}_{b}=\frac{B_{f 0} D^{2}}{u_{*}^{4} t}
$$

decreases with time. When $\mathrm{Ri}_{b}$ becomes lower than that of the critical value $\mathrm{Ri}_{b c}$, mixing takes place and the $\mathrm{XL}$ deepens so that $\mathrm{Ri}_{b}$ is equal to $\mathrm{Ri}_{b c}$. Thus, the deepening XLD can be expressed as

$$
D=u_{*}^{2} \sqrt{\frac{\mathrm{Ri}_{b c} t}{B_{f 0}}} .
$$

As time progresses, the velocity anomaly increases, but due to veering by Coriolis acceleration, the anomaly becomes largest in magnitude at half the inertial period and then begins to oscillate with the inertial period. The magnitude of the velocity anomaly averaged during the oscillating period can be approximated as

$$
\Delta u^{2}+\Delta v^{2} \sim\left(\frac{u_{*}^{2}}{f D}\right)^{2} .
$$

On the other hand, the buoyancy anomaly keeps increasing. As a consequence, the bulk Richardson number

$$
\mathrm{Ri}_{b} \sim \frac{B_{f 0} D^{2} f^{2} t}{u_{*}^{4}}
$$

increases with time and hence mixing is less likely to occur. Because the greatest XLD (MLD) can be expected when the mixing stops, that is, when the velocity anomaly becomes largest at half the inertial period $(t \sim \pi / f)$, the MLD is expressed from Eq. (32) as 


$$
D^{\mathrm{MAX}} \sim \sqrt{\mathrm{Ri}_{b c}} \frac{u_{*}^{2}}{\sqrt{B_{f 0} f}} \propto L_{Z 72}
$$

Therefore, this scenario successfully explains $D^{\mathrm{MAX}} \sim L_{Z 72}$ under constant strong buoyancy flux.

On the other hand, under the diurnally cycling surface buoyancy flux (DC experiment), the buoyancy anomaly develops with time as

$$
\Delta b=\frac{\int_{0}^{t} B_{f}\left(t_{0}\right) d t_{0}}{D},
$$

where $B_{f}(t)$ is the diurnally cycling surface buoyancy flux and the surface heating was set to start at $t=0$ for simplicity. The velocity anomaly is given by Eq. (29). Initially, its development follows Eq. (30), and the Richardson number can be written as

$$
\mathrm{Ri}_{b}=\frac{D^{2} \int_{0}^{t} B_{f}\left(t_{0}\right) d t_{0}}{u_{*}^{4} t^{2}}
$$

As time progresses, the velocity anomaly magnitude becomes largest at about half the inertial period as in the case with constant heat flux (DM experiment). After half the inertial period, the velocity anomaly is given by Eq. (33), and the bulk Richardson number can be approximated as

$$
\mathrm{Ri}_{b} \sim \frac{f^{2} D^{2} \int_{0}^{t} B_{f}\left(t_{0}\right) d t_{0}}{u_{*}^{4}}
$$

Under the diurnally cycling surface buoyancy flux, the buoyancy anomaly $\Delta b=\int_{0}^{t} B_{f}\left(t_{0}\right) d t_{0} / D$ [Eq. (36)] increases with time during the daytime due to surface heating, but decreases with time during the nighttime due to surface cooling. Therefore, the Richardson number is expected to be smallest at the end of the cooling (24h). [Here, we assumed that the velocity anomaly is given by Eq. (33) for simplicity. In fact, the velocity anomaly changes due to the inertial oscillation. Effect of this inertial oscillation is briefly described in 4.a.2.] Here, the two cases should be considered separately. In the first case where the velocity anomaly becomes largest before $24 \mathrm{~h}$ (e.g., $\pi / f \leq T_{24}$, corresponding to the higher-latitude cases), the velocity anomaly becomes largest at half the inertial period and becomes smaller thereafter. However, buoyancy stratification, being reduced by surface cooling, helps the XL to deepen until $t=T_{24}$ (Fig. 6). Therefore, the XLD becomes greatest at $t=T_{24}$, so that

$$
\begin{aligned}
D^{\mathrm{MAX}} & \sim \sqrt{\mathrm{Ri}_{b c}} \frac{u_{*}^{2}}{\sqrt{\int_{0}^{T_{24}} B_{f}(t) d t f}} \\
& =\sqrt{\mathrm{Ri}_{b c}} \frac{u_{*}^{2}}{\sqrt{B_{f 0} T_{24}} f} \propto L_{Z 72}\left(\frac{f T_{24}}{2 \pi}\right)^{-1 / 2},
\end{aligned}
$$

where $\int_{0}^{T_{24}} B_{f}(t) d t=B_{f 0} T_{24}$ was used. Thus, the above scenario requires the introduction of an additional nondimensional parameter $f T_{24} / 2 \pi$ at higher latitudes. In the other case where $\pi / f>T_{24}$, corresponding to the lower-latitude cases, the velocity anomaly continues to increase after $24 \mathrm{~h}$, and the XL continues to deepen until the velocity anomaly becomes larger in magnitude. Given that the velocity anomaly becomes largest on Day $n$ [here, $n$ satisfies $\left.(n-1) T_{24}<\pi / f \leq n T_{24}\right]$ and the XLD becomes greatest at the end of the day $n$, then the buoyancy anomaly at that time can be written as $B_{f 0} n T_{24}$. As a consequence, the greatest XLD (MLD) is expressed as

$$
D^{\mathrm{MAX}} \sim \sqrt{\mathrm{Ri}_{b c}} \frac{u_{*}^{2}}{\sqrt{\int_{0}^{n T_{24}} B_{f}(t) d t f}}=\sqrt{\mathrm{Ri}_{b c}} \frac{u_{*}^{2}}{\sqrt{B_{f 0} n T_{24} f}} .
$$

Note that $n$ changes with $f$ such that $n T_{24}$ is always close to $\pi / f$, that is, $n T_{24} \simeq \pi / f$. Using this relation, the MLD can be approximated as

$$
D^{\mathrm{MAX}} \sim \sqrt{\mathrm{Ri}_{b c}} \frac{u_{*}^{2}}{\sqrt{B_{f 0} f}} \propto L_{Z 72}
$$

This suggests that nondimensional parameter $f T_{24} / 2 \pi$ is not necessary at lower latitudes even under diurnally cycling surface heat fluxes.

The above scenario explains well the LES results in that the latitudinal dependence of the MLD changes at $f T_{24} / 2 \pi \cong 0.5\left(f \cong 4 \times 10^{-5} \mathrm{~s}^{-1}\right)$, and that the dependence is stronger at higher latitudes than at lower latitudes (Figs. 7a,9a). This scenario is also consistent with LES results in that the XL in the lower-latitude cases deepens by increasing velocity shear while the XL in the higher-latitude cases deepens at first by increasing velocity shear but at later times deepens with the help of weakening stratification (Fig. 6).

\section{2) VALIDATION WITH NUMERICAL SOLUTION AND COMPARISON WITH LES}

To validate the mechanism discussed in the previous subsection, we numerically solved Eqs. (20)-(22). Here, 
the velocity and buoyancy were set to be vertically uniform $\left(\nu_{T}, \kappa_{T} \rightarrow \infty\right)$ from the surface to depth $D$ while mixing was set to be suppressed $\left(\nu_{T}, \kappa_{T} \rightarrow 0\right)$ at a depth greater than $D$. The depth $D$ was determined so that $\mathrm{Ri}_{b}=\mathrm{Ri}_{b c}$. This corresponds to the model developed by Price et al. (1986) and hence hereafter, the model is referred to as the PWP bulk model. The critical value of the bulk Richardson number $\mathrm{Ri}_{b c}$ was set as 0.3 (Large et al. 1994; Kiehl et al. 1998). The initial and boundary conditions in the PWP bulk model were the same as those in the LES model. The Coriolis parameter $f$ was set as $1.0 \times 10^{-5} \times(14.5)^{k / 90} \mathrm{~s}^{-1}(k=0,1,2, \ldots, 90)$. The model ocean depth, the number of grids, and the vertical grid spacing were $2 L_{Z 72}, 200$, and $L_{Z 72} / 100$, respectively, and the time integration continued for 15 days.

Figure 10 shows the latitudinal dependence of the MLD in the PWP bulk model (hereafter referred to as $L_{\mathrm{PWP}}^{\mathrm{DM}}$ and $L_{\mathrm{PWP}}^{\mathrm{DC}}$ for the $\mathrm{DM}$ and $\mathrm{DC}$ experiments, respectively) for $u_{*}^{2}=1.0 \times 10^{-4} \mathrm{~m}^{2} \mathrm{~s}^{-2}$ and $H_{f 0}=$ $100 \mathrm{~W} \mathrm{~m}^{-2}$ (standard case). In the DM experiment, we found $L_{\mathrm{PWP}}^{\mathrm{DM}} \propto f^{-0.51}$ over the entire range of $f$, consistent with the previous analytical discussion in which $D^{\operatorname{MAX}} \propto f^{-1 / 2}$ [Eq. (35)]. In the DC experiment, the latitudinal dependence of the MLD changed at $f \cong 4 \times 10^{-5} \mathrm{~s}^{-1}$, with $L_{\mathrm{PWP}}^{\mathrm{DC}} \propto f^{-0.51}$ at smaller $f$ (lower latitudes) and $L_{\mathrm{PWP}}^{\mathrm{DC}} \propto f^{-0.95}$ at larger $f$ (higher latitudes). These results were also consistent with the analytical discussion [Eqs. (39) and (41)] in the previous subsection. Note, however, that the MLD in the PWP bulk model did not decrease monotonically with $f$; the local maximum of the MLD was found at $f \cong 10^{-4} \mathrm{~s}^{-1}$. This latitude was near the latitude of $3 \pi / f=T_{24}(f \cong$ $\left.1.1 \times 10^{-4} \mathrm{~s}^{-1}\right)$, where the velocity shear became largest at not only $8 \mathrm{~h}(\pi / f)$ but also $24 \mathrm{~h}(3 \pi / f)$ [Eq. (29)] because of the inertial oscillation of the wind-induced flow and contributed to the XL deepening. [Note that in the previous analytical scaling, the inertial oscillation was not considered after half the inertial period $(\pi / f)$.]

The PWP bulk model explains fairly well the most important feature in the MLD dependence observed in the LES; the diurnal cycle makes the MLD dependence larger at $f \geq \pi / T_{24}$. Note, however, that a couple of apparent differences are obvious between the PWP and LES results. One obvious difference is that the MLD in the LES model of the DM experiment depended more strongly on $f\left(L_{\mathrm{LES}}^{\mathrm{DM}} \propto f^{-0.59}\right)$ than the MLD in the PWP model $\left(L_{\mathrm{PWP}}^{\mathrm{DM}} \propto f^{-0.51}\right)$. Because $L_{\mathrm{LES}}^{\mathrm{DM}}$ agreed well with $L_{Z 02}$ (Figs. 8a,9a), this deviation was caused by Earth's rotation effect, which limited the ML deepening at smaller $B_{f 0}$ (or larger $f$ ) in LES but was not included in the PWP model. The second difference was

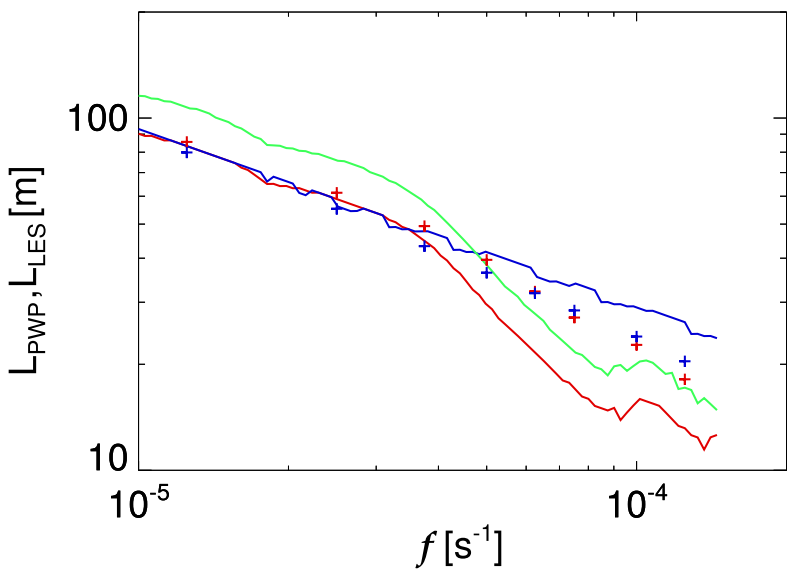

FIG. 10. Latitudinal dependence of the MLD in the standard DM (blue) and DC (red) experiments of LES (crosses) and PWP bulk model with $\mathrm{Ri}_{b c}=0.3$ (solid lines). Green solid line represents the results of the standard DC experiment in the PWP bulk model with $\mathrm{Ri}_{b c}=0.5$ during the cooling period.

found at the lower latitudes where in the LES, the MLD in the DC experiment $\left(L_{\mathrm{LES}}^{\mathrm{DC}}\right)$ was greater than that in the DM experiment $\left(L_{\mathrm{LES}}^{\mathrm{DM}}\right)$. However, in the PWP bulk model, they were nearly the same $\left(L_{\mathrm{PWP}}^{\mathrm{DC}} \cong\right.$ $\left.L_{\mathrm{PWP}}^{\mathrm{DM}}\right)$. This difference is thought to have come from the inappropriate choice of the critical bulk Richardson number $\mathrm{Ri}_{b c}$ for convective turbulence. In several previous studies (e.g., Zhang et al. 2014; Large et al. 1994), it was suggested that $\mathrm{Ri}_{b c}$ becomes larger under destabilizing buoyancy flux. In fact, the PWP bulk model with $\mathrm{Ri}_{b c}=0.5$ (Holtslag and Boville 1993) during cooling periods resulted in greater MLDs while the latitudinal dependence was unchanged (Fig. 10). The other difference was found at higher latitudes of the DC experiment where the latitudinal dependence of the MLD was stronger in the PWP bulk model than in the LES $\left(L_{\mathrm{PWP}}^{\mathrm{DC}} \propto f^{-0.95}\right.$ while $\left.L_{\mathrm{LES}}^{\mathrm{DC}} \propto f^{-0.83}\right)$. This difference is also speculated to be caused by the convection. Figure 6 shows that the divergence of vertical transport of the TKE due to convective motion had larger effects on the MLD in the higher-latitude standard case than in the lower-latitude standard case. This suggests that the convective turbulence contributed more to deepen the ML at higher latitudes than at lower latitudes, although the reason for this latitudinal difference in the convective transport is still unclear.

\section{b. Evaluation of diurnal cycle effects in the global ocean}

We showed in the previous section (section 3 ) that the diurnal cycle of the surface heat flux changed the MLD and SSW rate compared to those without the diurnal cycle. To see the potential impact of this change in the 
real ocean, the MLD and SSW rate with and without the diurnal cycle were evaluated over the global ocean using surface fluxes of atmospheric data and the scaling relations obtained from the present LES results.

As for the surface fluxes, we used the daily momentum flux (wind stress $\tau$ ) and net heat flux $H_{f}$ of the Japanese Ocean Flux Datasets with Use of Remote Sensing Observations (J-OFURO3) (Tomita et al. 2019), and the daily freshwater flux $(E-P)$ of National Centers for Environmental Prediction (NCEP) data (Kalnay et al. 1996) from 2001 to 2013, where $E$ and $P$ are the evaporation rate and the precipitation rate, respectively. The evaporation rate $E$ was estimated from the latent heat flux with the latent heat vaporization of water (Kara et al. 2000). These fluxes were converted to the friction velocity $u_{*}\left[=\left(\tau / \rho_{0}\right)^{1 / 2}\right]$ and buoyancy flux $B_{f}\left[=g \alpha H_{f} / C_{a} \rho_{0}-\beta(E-P) S\right]$. Here, $\rho_{0}=1.0 \times 10^{3} \mathrm{~kg} \mathrm{~m}^{-3}, \beta$ is the haline contraction rates of seawater, and $S$ is salinity. The thermal expansion rate $\alpha$ and the haline contraction rate $\beta$ were calculated with the equation of state for seawater (Jackett et al. 2006), using the mixed layer temperature and salinity of the mixed layer Argo dataset, gridpoint value (MILA-GPV) (Hosoda et al. 2010).

To estimate the MLD without the diurnal cycle $\left(L_{\mathrm{EST}}^{\mathrm{DM}}\right)$ from $u_{*}, B_{f}$, and $f$, Eq. (18) is used (i.e., $\left.L_{\mathrm{EST}}^{\mathrm{DM}}=L_{Z 02}^{\mathrm{DM}}\right)$. To estimate the MLD with the diurnal cycle $\left(L_{\mathrm{EST}}^{\mathrm{DC}}\right)$, we used the following equation

$L_{\mathrm{EST}}^{\mathrm{DC}}= \begin{cases}1.1\left|\frac{f T_{24}}{2 \pi}\right|^{0.011} L_{Z 02}^{\mathrm{DM}} & f T_{24} / 2 \pi<0.5, \\ 0.99\left|\frac{f T_{24}}{2 \pi}\right|^{-0.18} L_{Z 02}^{\mathrm{DM}} & f T_{24} / 2 \pi \geq 0.5,\end{cases}$

which were obtained from the LES data shown in Fig. 9.

First, we compared $L_{\mathrm{EST}}^{\mathrm{DM}}$ and $L_{\mathrm{EST}}^{\mathrm{DC}}$ with the observed MLD $\left(L_{\mathrm{OBS}}\right)$ of MILA-GPV. For this comparison, we averaged $u_{*}$ and $B_{f}$ onto $2^{\circ} \times 2^{\circ}$ over 10 days and calculated the $L_{\mathrm{EST}}$ values, because the MLD of MILA-GPV ( $\left.L_{\mathrm{OBS}}\right)$ was averaged onto these resolutions. The observed MLD ( $\left.L_{\mathrm{OBS}}\right)$ to be compared with $L_{\text {EST }}$ was obtained by selecting the MLDs that were expected to be shoaled by surface fluxes. For this selection, the same procedures as those of Yoshikawa (2015) were applied to the MILA-GPV data. In the present study, MLDs at lower latitudes than $10^{\circ}$ were not analyzed because they are less likely balanced with the 10-day surface fluxes due to longer inertial periods ( $\sim 3$ days). We further discarded the MLD data smaller than $15 \mathrm{~m}$ because the MLD of MILA-GPV, defined as the depth at which the temperature or density differs from that at $10-\mathrm{m}$ depth by a threshold value $(0.2 \mathrm{~K}$ or

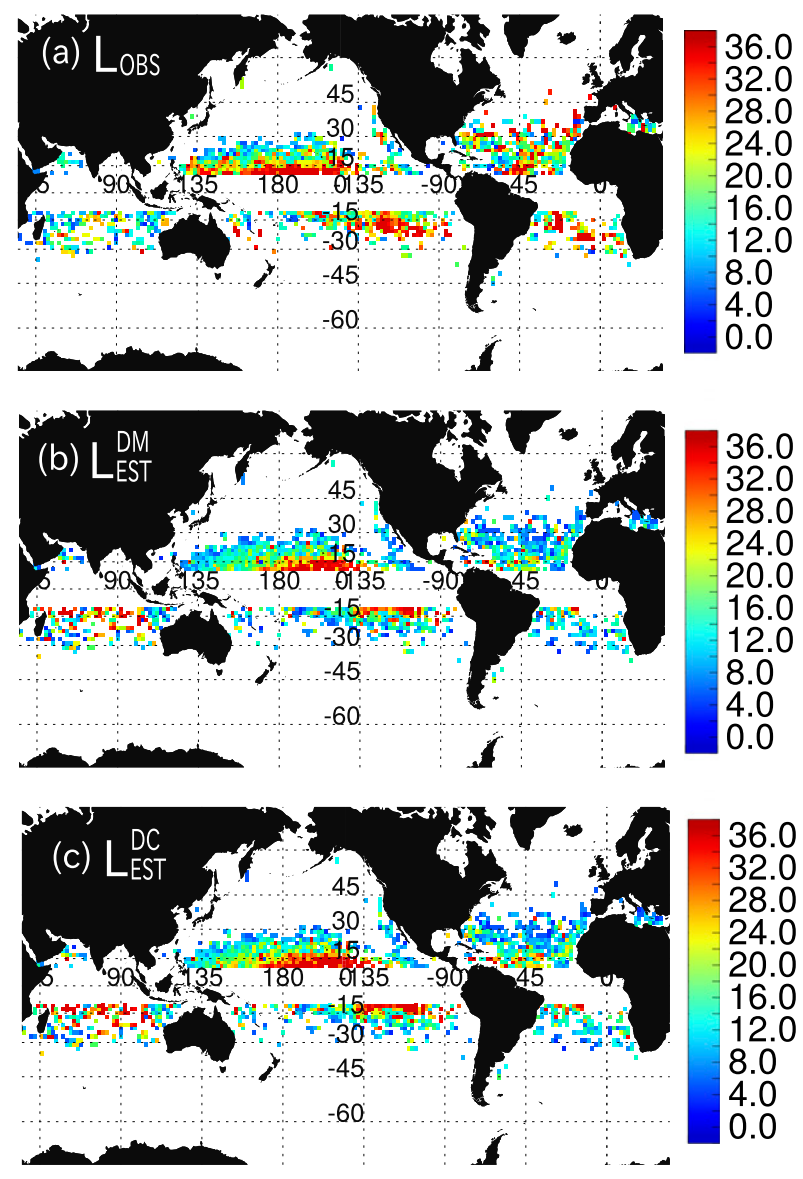

FIG. 11. Global distribution of the (a) $L_{\mathrm{OBS}}$ (observed MLD), (b) $L_{\mathrm{EST}}^{\mathrm{DM}}$ (estimated MLD without the diurnal cycle), and (c) $L_{\mathrm{EST}}^{\mathrm{DC}}$ (estimated MLD with the diurnal cycle). The white area represents the lack of analyzed data.

$0.03 \mathrm{~kg} \mathrm{~m}^{-3}$ ), were more noisy and less reliable. Moreover, in order to select the MLDs influenced by the diurnal cycle effects, we selected the MLD data at the grid and time in which the net shortwave radiation of J-OFURO3 exceeded the $80 \%$ of the clear-sky mean daily insolation (Seckel and Beaudry 1973; Reed 1977).

Figure 11 shows the global distribution of $L_{\mathrm{OBS}}$, $L_{\mathrm{EST}}^{\mathrm{DM}}$, and $L_{\mathrm{EST}}^{\mathrm{DC}}$. The small number of data at high latitudes was due to a short period under the clear-sky condition. The overall features in all of the MLDs were similar; they decrease with latitudes. This similarity suggests that the effects of the diurnal cycle on the MLD are not apparent to the first order. However, the scatterplots between $L_{\mathrm{EST}}^{\mathrm{DM}}$ and $L_{\mathrm{OBS}}$ (Fig. 12a) and between $L_{\mathrm{EST}}^{\mathrm{DC}}$ and $L_{\mathrm{OBS}}$ (Fig. $12 \mathrm{~b}$ ) show that $L_{\mathrm{EST}}^{\mathrm{DC}}$ was slightly better than $L_{\mathrm{EST}}^{\mathrm{DM}}$ because the slope of the regression line between $L_{\mathrm{EST}}^{\mathrm{DC}}$ and $L_{\mathrm{OBS}}$ was closer to one and the root-mean-square between $L_{E S T}^{D C}$ and $L_{\mathrm{OBS}}$ was smaller than those between $L_{\mathrm{EST}}^{\mathrm{DM}}$ and $L_{\mathrm{OBS}}$. Note that large scatter made the significance of $L_{\mathrm{EST}}^{\mathrm{DM}} / L_{\mathrm{OBS}} \neq 1$ and 

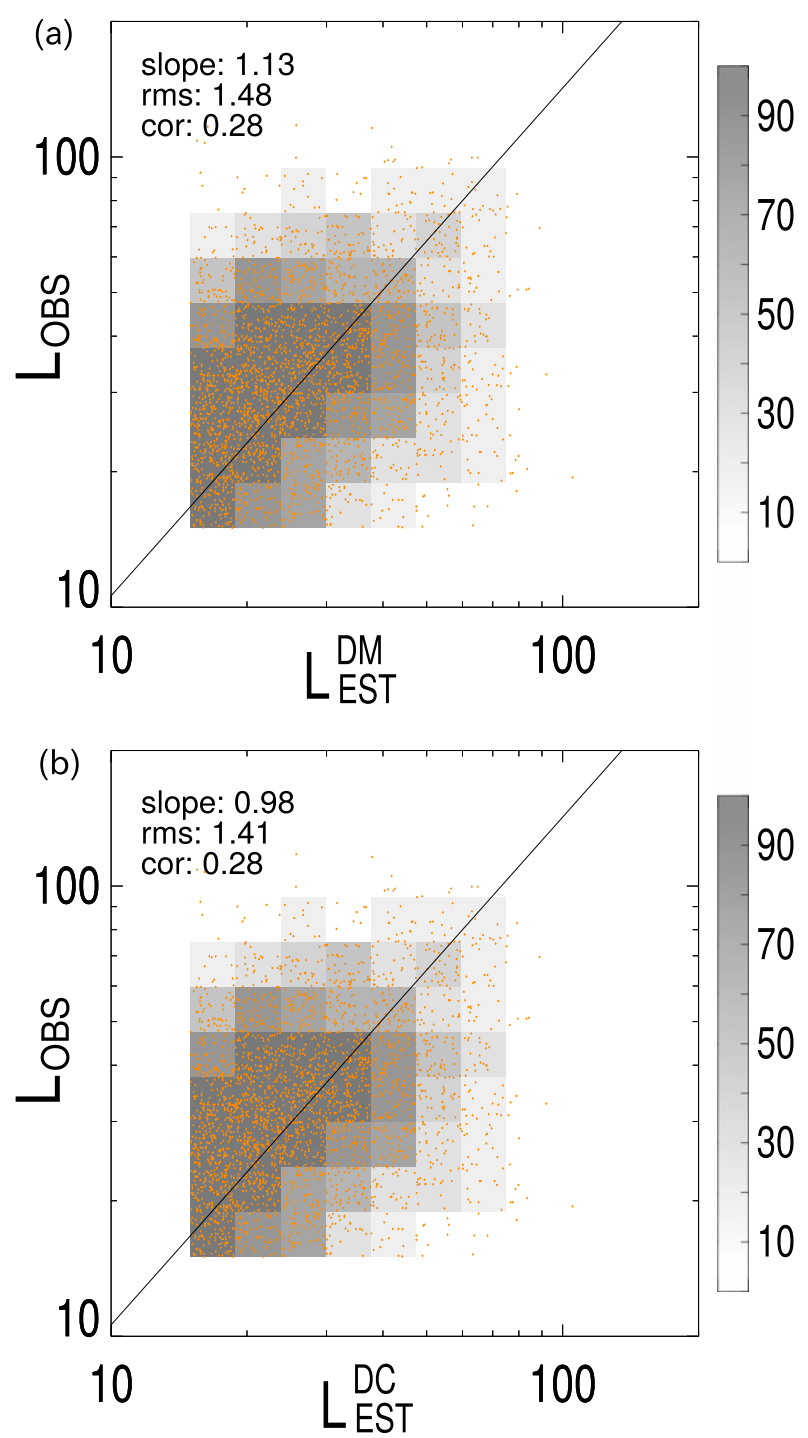

FIG. 12. Scatterplots between (a) $L_{\mathrm{EST}}^{\mathrm{DM}}$ and $L_{\mathrm{OBS}}$ and between (b) $L_{\mathrm{EST}}^{\mathrm{DC}}$ and $L_{\mathrm{OBs}}$. Gray shading represents the numbers of data in a square box with dimensions of $\Delta\left(\log _{10} L_{\mathrm{EST}}\right) \times$ $\Delta\left(\log _{10} L_{\mathrm{OBS}}\right)=0.1 \times 0.1$.

$L_{\mathrm{EST}}^{\mathrm{DC}} / L_{\mathrm{OBS}} \neq 1$ were very high $(100 \%$ and $89 \%$, respectively), though the slightly lower significance of the latter than that of the former does not deny the better performance of $L_{\mathrm{EST}}^{\mathrm{DC}}$ than $L_{\mathrm{EST}}^{\mathrm{DM}}$. Large scatters seem to be partly related to the fact that $L_{\mathrm{EST}}$ was estimated from 10-day averaged fluxes while $L_{\mathrm{OBS}}$ was calculated from instantaneous measurement(s) in 10 days. Large scatters may also be related to processes not considered in our idealized simulation (e.g., temporal variation of winds).

Next, we investigated the potential impact of the difference in SSW with and without the diurnal cycle using Eq. (17). The friction velocity and buoyancy flux from
2001 to 2010 were averaged into monthly climatological data on a $2^{\circ} \times 2^{\circ}$ grid. The SSW rate without the diurnal cycle effects was scaled as

$$
\frac{\partial\left\langle\overline{\theta_{\mathrm{EST}}^{\mathrm{DM}}}\right\rangle}{\partial t}=0.95 \frac{H_{f 0}}{\rho C_{s} L_{\mathrm{EST}}^{\mathrm{DM}}},
$$

and the SSW rate with the diurnal cycle effects was scaled as

$$
\frac{\partial\left\langle\overline{\theta_{\mathrm{EST}}^{\mathrm{DC}}}\right\rangle}{\partial t}=0.93 \frac{H_{f 0}}{\rho C_{s} L_{\mathrm{EST}}^{\mathrm{DC}}} .
$$

Proportional coefficients in the above Eqs. [0.95 in Eq. (43) and 0.93 in Eq. (44)] were determined from LES data. Figure 13 shows the SSWs for one month (the SSW rate $\times 30$ days) in late spring (June in the Northern Hemisphere and December in the Southern Hemisphere) evaluated with Eqs. (43) (without the diurnal cycle, Fig. 13c) and (44) (with the cycle, Fig. 13d). Both of the SSWs showed a similar pattern; they were large $(\sim 6 \mathrm{~K})$ at midlatitudes and small $(<1 \mathrm{~K})$ at low latitudes. This spatial pattern was largely determined by the MLD (Figs. 13a,b). The evaluated SSWs were larger than the observed SSW (calculated from the World Ocean Atlas climatological data; Locarnini et al. 2013) by a factor of 3 (Fig. 13e), probably because turbulent downward heat transfer across the MLD (e.g., Hosoda et al. 2015) was not considered in our evaluation. Therefore, the evaluated SSWs were overestimated, and the SSWs in the real ocean will be less than onethird of the evaluated values. Note, however, that the SSW with the diurnal cycle was larger than without the cycle by $0.3-0.6 \mathrm{~K}$ at mid- and high latitudes, especially in the North Pacific (Fig. 13f), suggesting that the diurnal cycle could increase the SST by an order of $0.1 \mathrm{~K}$. This difference is as large as the difference caused by the rectified vertical heat transfer due to the diurnal cycle, which is suggested to affect atmospheric circulation (e.g., Guemas et al. 2013; Large and Caron 2015). Thus, the SST increase due to the diurnal cycle can have nonnegligible impacts at mid- and high latitudes, although the periods under the clear-sky condition are short and hence the diurnal cycle impact may be small at high latitudes.

\section{Summary}

This study investigated the diurnal cycle effects on the MLD and SSW in the heating season using LESs. The results showed that the MLD without a diurnal cycle followed $L_{Z 02}$ as shown in previous studies (Zilitinkevich et al. 2002; Yoshikawa 2015). However, 

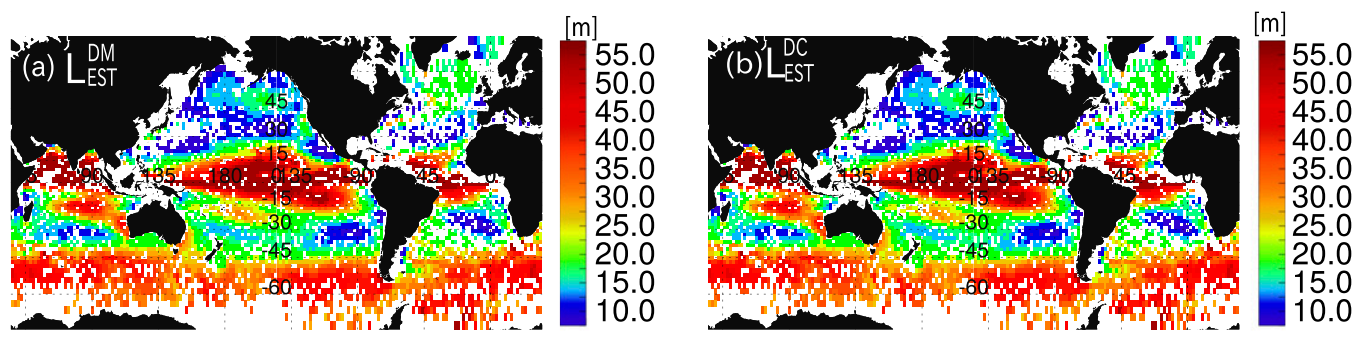

$[\mathrm{K} / \mathrm{month}]$
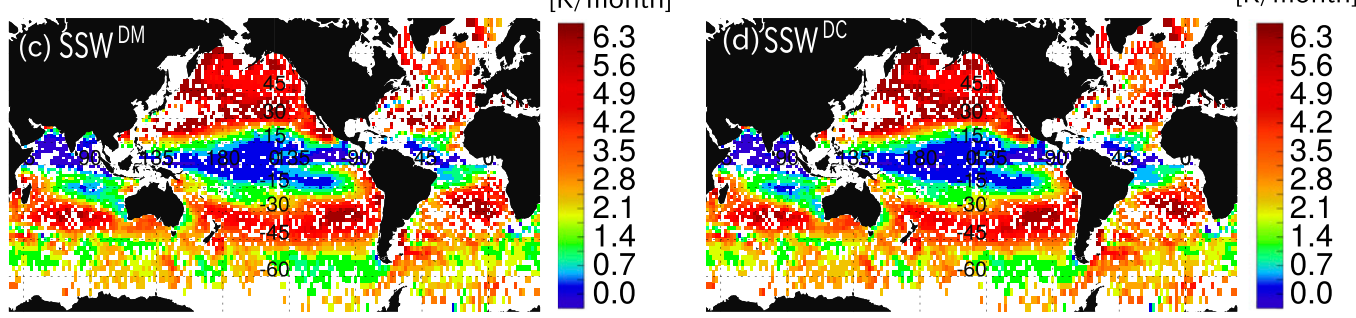

$[\mathrm{K} / \mathrm{month}]$
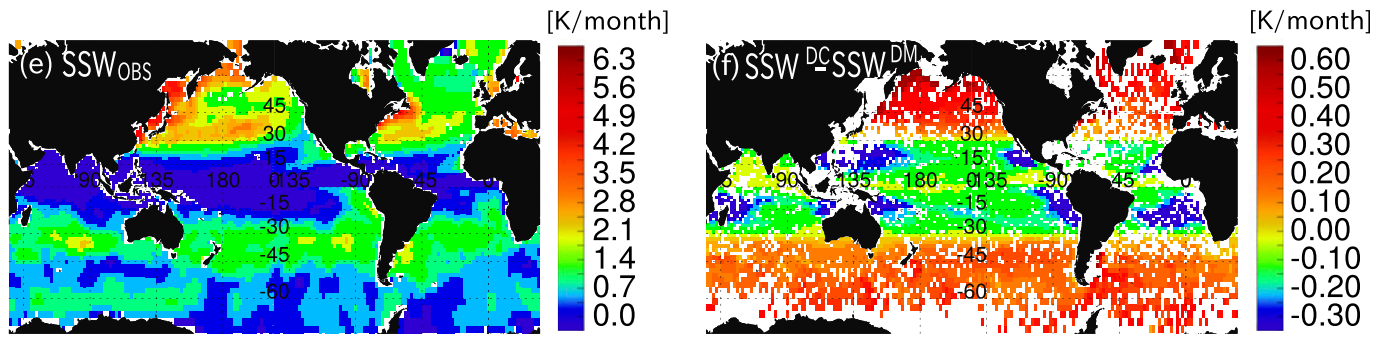

FIG. 13. Global distribution of (a) $L_{\mathrm{EST}}^{\mathrm{DM}}$, (b) $L_{\mathrm{EST}}^{\mathrm{DC}}$, (c) $\mathrm{SSW}$ without the diurnal cycle $\left(\mathrm{SSW}_{\mathrm{EST}}^{\mathrm{DM}}\right)$ estimated with Eq. (43), and (d) SSW with the diurnal cycle (SSW DC $)$ estimated with Eq. (44) in June in the Northern Hemisphere and in December in the Southern Hemisphere. (e) Observed SSW (SSW ${ }_{\mathrm{OBS}}$ ) calculated from the World Ocean Atlas climatological data (Locarnini et al. 2013), and (f) difference between the estimated SSWs $\left(\mathrm{SSW}_{\mathrm{EST}}^{\mathrm{DC}}-\mathrm{SSW}_{\mathrm{EST}}^{\mathrm{DM}}\right)$.

the inclusion of a diurnal cycle changed this scaling; the MLD at lower latitudes $\left(f \leq 4 \times 10^{-5} \mathrm{~s}^{-1}\right)$ almost follows $L_{Z 02}$, (although the proportional coefficient is larger than that without the diurnal cycle), but the MLD at higher latitudes $\left(f>4 \times 10^{-5} \mathrm{~s}^{-1}\right)$ followed $L_{Z 02}\left(f T_{24} / 2 \pi\right)^{-0.18}$ where $T_{24}(=24 \mathrm{~h})$ was the period of the diurnal cycle. As a result, the diurnal cycle made the MLD at lower (higher) latitudes greater (smaller) by $\leq 10 \%$.

The SSW rate was also changed by the diurnal cycle due to the MLD change. At mid- and high latitudes, the MLD change could induce SSW of $\geq 0.1 \mathrm{~K}$ in late spring. This warming is comparable to the daily mean SST increase due to the rectified vertical heat transfer induced by the diurnal cycle, which has been suggested in previous studies (Guemas et al. 2013; Large and Caron 2015) to have impacts on climate variability, such as the Madden-Julian oscillation (Bernie et al. 2005; Woolnough et al. 2007). This indicates that a change in the MLD caused by the diurnal cycle found in the present studies also has a potential impact on longer scale variability of the ocean and atmosphere as well.
The diurnal cycle may also change quantities of other MLD-related processes. For example, the diurnal cycle may increase the subduction rate due to lateral induction by increasing the meridional gradient of the MLD.

To quantify the diurnal cycle effects on large-scale MLD-related processes such as climate variability, the subduction of subsurface water and the blooming of phytoplankton, mixed layer schemes should be validated and improved to represent the diurnal cycle effects on the MLD properly. For example, use of the PWP scheme may not be appropriate for these purposes, because it does not quantitatively reproduce MLD dependence on latitude [section $4 \mathrm{a}(2)$ ]. Then, simulations with larger models such as OGCMs and CGCMs that incorporate the proper mixed layer scheme will be necessary.

Finally, it should be remarked that our model was highly idealized, and several processes such as the temporal variation of winds and LCs were not considered in this study. It should be noted that the effects of LCs depend on various parameters such as wave height, 
wavelength, wave age, and wave direction relative to wind direction (e.g., Harcourt and D'Asaro 2008; Van Roekel et al. 2012), so including these external parameters makes the diurnal cycle effects found in this study vague. These processes might need to be examined for more quantitative estimations of the MLD and SSW. More LES-based studies will be required for these purposes. These will be the focus of our future studies.

Acknowledgments. We express our thanks two anonymous reviewers for their instructive comments. This work was supported by JSPS KAKENHI Grant Numbers JP15H05824 and JP16H02226. Discussions were also helpful at the meeting held as the Collaborative Research Program (28A0-S4) of Research Institute for Applied Mechanics, Kyushu University.

\section{REFERENCES}

Bernie, D. J., S. J. Woolnough, J. M. Slingo, and E. Guilyardi, 2005: Modeling diurnal and intraseasonal variability of the ocean mixed layer. J. Climate, 18, 1190-1202, https://doi.org/10.1175/ JCLI3319.1.

Businger, J. a., J. C. Wyngaard, Y. Izumi, and E. F. Bradley, 1971: Flux-profile relationships in the atmospheric surface layer. J. Atmos. Sci., 28, 181-189, https://doi.org/10.1175/ 1520-0469(1971)028<0181:FPRITA > 2.0.CO;2.

Deardorff, J. W., 1980: Stratocumulus-capped mixed layers derived from a three-dimensional model. Bound.-Layer Meteor., 18, 495-527, https://doi.org/10.1007/BF00119502.

Ezer, T., 2000: On the seasonal mixed layer simulated by a basinscale ocean model and the Mellor-Yamada turbulence scheme. J. Geophys. Res., 105, 16843-16856, https://doi.org/ 10.1029/2000JC900088.

Gerbi, G. P., J. H. Trowbridge, E. A. Terray, A. J. Plueddemann, and T. Kukulka, 2009: Observations of turbulence in the ocean surface boundary layer: Energetics and transport. J. Phys. Oceanogr., 39, 1077-1096, https://doi.org/10.1175/ 2008JPO4044.1.

Goh, G., and Y. Noh, 2013: Influence of the Coriolis force on the formation of a seasonal thermocline. Ocean Dyn., 63, 10831092, https://doi.org/10.1007/s10236-013-0645-x.

Grant, A. L. M., and S. E. Belcher, 2009: Characteristics of Langmuir turbulence in the ocean mixed layer. J. Phys. Oceanogr., 39, 1871-1887, https://doi.org/10.1175/2009JPO4119.1.

Guemas, V., D. Salas-Mélia, M. Kageyama, H. Giordani, and A. Voldoire, 2013: Impact of the ocean diurnal cycle on the North Atlantic mean sea surface temperatures in a regionally coupled model. Dyn. Atmos. Oceans, 60, 28-45, https:// doi.org/10.1016/j.dynatmoce.2013.01.001.

Harcourt, R. R., and E. A. D'Asaro, 2008: Large-eddy simulation of Langmuir turbulence in pure wind seas. J. Phys. Oceanogr., 38, 1542-1562, https://doi.org/10.1175/2007JPO3842.1.

Holtslag, A. A. M., and B. A. Boville, 1993: Local versus nonlocal boundary-layer diffusion in a global climate model. J. Climate, 6, 1825-1842, https://doi.org/10.1175/1520-0442(1993)006<1825: LVNBLD $>2.0 . \mathrm{CO} ; 2$.

Hosoda, S., T. Ohira, K. Sato, and T. Suga, 2010: Improved description of global mixed-layer depth using Argo profiling floats. J. Oceanogr., 66, 773-787, https://doi.org/10.1007/ s10872-010-0063-3.

— M. Nonaka, T. Tomita, B. Taguchi, H. Tomita, and N. Iwasaka, 2015: Impact of downward heat penetration below the shallow seasonal thermocline on the sea surface temperature. J. Oceanogr., 71, 541-556, https://doi.org/10.1007/s10872-015-0275-7.

Huang, C. J., F. Qiao, and D. Dai, 2014: Evaluating CMIP5 simulations of mixed layer depth during summer. J. Geophys. Res., 119, 2568-2582, https://doi.org/10.1002/2013JC009535.

Ide, Y., and Y. Yoshikawa, 2016: Effects of diurnal cycle of surface heat flux on wind-driven flow. J. Oceanogr., 72, 263-280, https://doi.org/10.1007/s10872-015-0328-y.

Jackett, D. R., T. J. McDougall, D. G. Wright, and S. M. Griffies, 2006: Algorithms for density, potential temperature, conservative temperature, and the freezing temperature of seawater. J. Atmos. Oceanic Technol., 23, 1709-1728, https://doi.org/ 10.1175/JTECH1946.1.

Kalnay, E., and Coauthors, 1996: The NCEP/NCAR 40-Year Reanalysis Project. Bull. Amer. Meteor. Soc., 77, 437471, https://doi.org/10.1175/1520-0477(1996)077<0437: TNYRP $>2.0 . \mathrm{CO} ; 2$.

Kara, A. B., P. A. Rochford, and H. E. Hurlburt, 2000: Efficient and accurate bulk parameterizations of air-sea fluxes for use in general circulation models. J. Atmos. Oceanic Technol., 17, 1421-1438, https://doi.org/10.1175/1520-0426(2000)017<1421: $\mathrm{EAABPO}>2.0 . \mathrm{CO} ; 2$.

Kiehl, J. T., J. J. Hack, and J. W. Hurrell, 1998: The energy budget of the NCAR Community Climate Model: CCM3. J. Climate, 11, 1151-1178, https://doi.org/10.1175/15200442(1998)011<1151:TEBOTN>2.0.CO;2.

Large, W. G., and J. M. Caron, 2015: Diurnal cycling of sea surface temperature, salinity, and current in the CESM coupled climate model. J. Geophys. Res., 120, 3711-3729, https://doi.org/ 10.1002/2014JC010691.

_ J. C. Mcwilliams, and S. C. Doney, 1994: Oceanic vertical mixing: A review and a model with a nonlocal boundary-layer parameterization. Rev. Geophys., 32, 363-403, https://doi.org/ 10.1029/94RG01872.

Li, Y., W. Han, W. Wang, and M. Ravichandran, 2016: Intraseasonal variability of sst and precipitation in the Arabian Sea during the Indian summer monsoon: Impact of ocean mixed layer depth. J. Climate, 29, 7889-7910, https://doi.org/10.1175/ JCLI-D-16-0238.1.

Locarnini, R. A., and Coauthors, 2013: Temperature. Vol. 1, World Ocean Atlas 2013, NOAA Atlas NESDIS 73, 40 pp., http:// data.nodc.noaa.gov/woa/WOA13/DOC/woa13_vol1.pdf.

Marshall, J. C., R. G. Williams, and A. J. G. Nurser, 1993: Inferring the subduction rate and period over the North Atlantic. J. Phys. Oceanogr., 23, 1315-1329, https://doi.org/10.1175/ 1520-0485(1993)023<1315:ITSRAP $>2.0$.CO;2.

McWilliams, J. C., P. P. Sullivan, and C. H. Moeng, 1997: Langmuir turbulence in the ocean. J. Fluid Mech., 334, 1-30, https:// doi.org/10.1017/S0022112096004375.

Noh, Y., and Y. Choi, 2018: Reply to "Comments on 'Langmuir turbulence and surface heating in the ocean surface boundary layer.", J. Phys. Oceanogr., 48, 455-458, https://doi.org/ 10.1175/JPO-D-17-0135.1.

- H. S. Min, and S. Raasch, 2004: Large eddy simulation of the ocean mixed layer: the effects of wave breaking and Langmuir circulation. J. Phys. Oceanogr., 34, 720-735, https://doi.org/ 10.1175/1520-0485(2004)034<0720:LESOTO>2.0.CO;2.

_ G. Goh, S. Raasch, and M. Gryschka, 2009: Formation of a diurnal thermocline in the ocean mixed layer simulated by 
LES. J. Phys. Oceanogr., 39, 1244-1257, https://doi.org/10.1175/ 2008JPO4032.1.

Obata, A., J. Ishizaka, and M. Endoh, 1996: Global verification of critical depth theory for phytoplankton bloom with climatological in situ temperature and satellite ocean color data. J. Geophys. Res., 101, 20 657-20 667, https://doi.org/10.1029/ 96JC01734.

Pollard, R. T., P. B. Rhines, and R. O. R. Y. Thompson, 1972: The deepening of the wind-mixed layer. Geophys. Fluid Dyn., 4, 381-401, https://doi.org/10.1080/03091927208236105.

Price, J. F., R. A. Weller, and R. Pinkel, 1986: Diurnal cycling: Observations and models of the upper ocean response to diurnal heating, cooling, and wind mixing. J. Geophys. Res., 91, 8411, https://doi.org/10.1029/JC091iC07p08411.

Reed, R. K., 1977: On estimating insolation over the ocean. J. Phys. Oceanogr., 7, 482-485, https://doi.org/10.1175/ 1520-0485(1977)007<0482:OEIOTO >2.0.CO;2.

Roxy, M., Y. Tanimoto, B. Preethi, P. Terray, and R. Krishnan, 2013: Intraseasonal SST-precipitation relationship and its spatial variability over the tropical summer monsoon region. Climate Dyn., 41, 45-61, https://doi.org/10.1007/s00382-012-1547-1.

Seckel, G. R., and F. H. Beaudry, 1973: The radiation from sun and sky over the North Pacific Ocean. Eos, Trans. Amer. Geophys. Union, 54 (11), 1114, https://doi.org/10.1029/ EO054i011p01060.

Sutherland, G., G. Reverdin, L. Marié, and B. Ward, 2014: Mixed and mixing layer depths in the ocean surface boundary. Geophys. Res. Lett., 41, 8469-8476, https://doi.org/10.1002/ 2014GL061939.

Sverdrup, H., 1953: On conditions for the vernal blooming of phytoplankton. ICES J. Mar. Sci., 18, 287-295, https://doi.org/ 10.1093/icesjms/18.3.287.
Tomita, H., T. Hihara, S. Kako, M. Kubota, and K. Kutsuwada, 2019: An introduction to J-OFURO3, a third-generation Japanese ocean flux data set using remote-sensing observations. J. Oceanogr., 75, 171-194, https://doi.org/10.1007/ s10872-018-0493-x.

Van Roekel, L. P., B. Fox-Kemper, P. P. Sullivan, P. E. Hamlington, and S. R. Haney, 2012: The form and orientation of Langmuir cells for misaligned winds and waves. J. Geophys. Res., 117, C05001, https://doi.org/10.1029/2011JC007516.

Woolnough, S. J., F. Vitart, and M. Balmaseda, 2007: The role of the ocean in the Madden-Julian Oscillation: Implications for MJOprediction. Quart. J. Roy. Meteor. Soc., 133, 117-128, https://doi.org/10.1002/qj.4.

Yoshikawa, Y., 2015: Scaling surface mixing/mixed layer depth under stabilizing buoyancy flux. J. Phys. Oceanogr., 45, 247258, https://doi.org/10.1175/JPO-D-13-0190.1.

Zhang, Y., Z. Gao, D. Li, Y. Li, N. Zhang, X. Zhao, and J. Chen, 2014: On the computation of planetary boundary-layer height using the bulk Richardson number method. Geosci. Model Dev., 7, 2599-2611, https://doi.org/10.5194/gmd-7-2599-2014.

Zilitinkevich, S. S., 1972: On the determination of the height of the Ekman boundary layer. Bound-Layer Meteor., 3, 141-145, https://doi.org/10.1007/BF02033914.

—, A. Baklanov, J. Rost, A.-s. Smedman, V. Lykosov, and P. Calanca, 2002: Diagnostic and prognostic equations for the depth of the stably stratified Ekman boundary layer. Quart. J. Roy. Meteor. Soc., 128, 25-46, https://doi.org/10.1256/ 00359000260498770.

- I. Esau, and A. Baklanov, 2007: Further comments on the equiliburium height of neutral and stable planetary boundary layer. Quart. J. Roy. Meteor. Soc., 133, 265-271, https://doi.org/ 10.1002/qj.27. 